\title{
The Growing Role of Noninvasive Ventilation in Patients Requiring Prolonged Mechanical Ventilation
}

\author{
Dean R Hess PhD RRT FAARC
}

\author{
Introduction \\ Obstructive Lung Disease \\ Chronic Obstructive Pulmonary Disease \\ Cystic Fibrosis \\ Restrictive Lung Disease \\ Restrictive Thoracic Disorders \\ Obesity Hypoventilation Syndrome \\ Neuromuscular Disease \\ Equipment Needs \\ Interface \\ Ventilator \\ Approaches to Intolerance \\ Summary
}

For many patients with chronic respiratory failure requiring ventilator support, noninvasive ventilation (NIV) is preferable to invasive support by tracheostomy. Currently available evidence does not support the use of nocturnal NIV in unselected patients with stable COPD. Several European studies have reported benefit for high intensity NIV, in which setting of inspiratory pressure and respiratory rate are selected to achieve normocapnia. There have also been studies reporting benefit for the use of NIV as an adjunct to exercise training. NIV may be useful as an adjunct to airway clearance techniques in patients with cystic fibrosis. Accumulating evidence supports the use of NIV in patients with obesity hypoventilation syndrome. There is considerable observational evidence supporting the use of NIV in patients with chronic respiratory failure related to neuromuscular disease, and one randomized controlled trial reported that the use of NIV was life-prolonging in patients with amyotrophic lateral sclerosis. A variety of interfaces can be used to provide NIV in patients with stable chronic respiratory failure. The mouthpiece is an interface that is unique in this patient population, and has been used with success in patients with neuromuscular disease. Bi-level pressure ventilators are commonly used for NIV, although there are now a new generation of intermediate ventilators that are portable, have a long battery life, and can be used for NIV and invasive applications. Pressure support ventilation, pressure controlled ventilation, and volume controlled ventilation have been used successfully for chronic applications of NIV. New modes have recently become available, but their benefits await evidence to support their widespread use. The success of NIV in a given patient population depends on selection of an appropriate patient, selection of an appropriate interface, selection of an appropriate ventilator and ventilator settings, the skills of the clinician, the motivation of the patient, and the support of the family. Key words: amyotrophic lateral sclerosis; bi-level pressure ventilation; chronic obstructive pulmonary disease; cystic fibrosis; Duchenne muscular dystrophy; noninvasive ventilation; obesity hypoventilation syndrome; restrictive thoracic disorder. [Respir Care 2012;57(6):900-918. (c) 2012 Daedalus Enterprises] 


\section{Introduction}

Noninvasive ventilation (NIV) is the use of assisted ventilation without an artificial airway (eg, tracheostomy tube or endotracheal tube). Dating back to the polio epidemic of the 1950s, NIV was first applied using negative pressure applied to the chest wall. But today it is almost always applied as positive pressure to the airway opening. Just as the use of NIV has increased in the acute care hospital setting, its use has increased as well in the longterm care hospital and the home for the management of patients requiring prolonged mechanical ventilation. Home NIV is used primarily for patients with obstructive lung disease, neuromuscular disease, obesity hypoventilation syndrome (OHS), and restrictive chest wall disease. Although many patients with chronic critical illness require respiratory support, most patients receiving NIV for prolonged mechanical ventilation do not have chronic critical illness.

Janssens et al ${ }^{1}$ reported that, in 2000 in the Geneva Lake area of Switzerland, the 2 major uses of NIV were for treatment of COPD and OHS. In this study, home NIV therapy was associated with a significant reduction in hospitalizations in all groups studied. Adherence to treatment was satisfactory, with reported under-users or interruption of therapy for non-adherence of $15 \%$. In a survey by LloydOwen et $\mathrm{al}^{2}$ in 2001-2002, the use of home mechanical ventilation was found to be very variable throughout Europe. There were fewer uses for primary lung disease than for neuromuscular disease and chest wall restriction. The majority $(87 \%)$ of patients were ventilated with NIV. Divo et $\mathrm{al}^{3}$ conducted a survey in Massachusetts to estimate the prevalence and locations of prolonged and home ventilation in 2006. Of the patients included in the survey, 225 were receiving NIV and the remainder had a tracheostomy. The results of these studies suggest that NIV is used more commonly for prolonged mechanical ventilation in Europe than in Massachusetts.

Dr Hess is affiliated with the Department of Respiratory Care, Massachusetts General Hospital, and the Department of Anesthesia, Harvard Medical School, Boston, Massachusetts.

Dr Hess presented a version of this paper at the 49th RESPIRATORY CARE Journal Conference, "The Chronically Critically Ill Patient," held September 9-10, 2011, in St Petersburg, Florida.

Dr Hess has disclosed relationships with Philips Respironics, ResMed, Covidien, Breathe Technology, and Pari.

Correspondence: Dean R Hess PhD RRT FAARC, Respiratory Care, Ellison 401, Massachusetts General Hospital, 55 Fruit Street, Boston MA 02114. E-mail: dhess@partners.org.

DOI: $10.4187 /$ respcare.01692
There are several reasons why NIV might be preferable to tracheostomy for prolonged mechanical ventilation. First, many patients use the ventilator for only part of the day, most often at night. Given the acute and long-term complications of tracheostomy, ${ }^{4}$ it would not seem prudent to perform tracheostomy for part-time ventilation. Issues related to the care of the tracheostomy complicate management for both the patient and caregivers. Finally, the presence of a tracheostomy is unsightly and might impact the patient's quality of life. However, inconsistent findings have been reported in studies that have assessed quality of life in patients receiving NIV and those with tracheostomy. ${ }^{5-8}$ Thus, patient preference should be given consideration in clinical decisions of NIV versus tracheostomy. The opinions of physicians and respiratory therapists might not be consistent with patient preference.

\section{Obstructive Lung Disease}

\section{Chronic Obstructive Pulmonary Disease}

Given the success of NIV during COPD exacerbation, ${ }^{9}$ one might expect that this therapy might also be helpful in patients with stable COPD. NIV at night might improve gas exchange, it could improve sleep quality, and it could rest chronically fatigued respiratory muscles. Moreover, symptom management and prevention of exacerbations are important in reducing morbidity and mortality associated with COPD. There have been numerous randomized controlled trials ${ }^{10-18}$ and observational studies ${ }^{19-31}$ that have evaluated the use of NIV in patients with stable COPD. It is fair to say that the use of NIV for this indication is controversial. ${ }^{32,33}$

A meta-analysis by Wijkstra of 4 studies ${ }^{10,11,19,23}$ of nocturnal NIV in patients with COPD was published in $2003 .{ }^{34}$ NIV was applied via a nasal or oronasal mask for at least $5 \mathrm{~h} / \mathrm{d}$ for at least 3 weeks. The authors of this meta-analysis concluded that NIV support did not improve lung function, gas exchange, or sleep efficiency.

A more recent systematic review was published by Kolodziej et al. ${ }^{35}$ They included 6 randomized controlled trials ${ }^{10-15}$ and 9 observational studies ${ }^{19-27}$ in their review. The authors concluded that NIV use in patients with severe stable COPD may improve gas exchange, exercise tolerance, dyspnea, work of breathing, frequency of hospitalization, health-related quality of life (HRQL), and functional status. However, these findings were based primarily on the results of the observational studies. For example, improved gas exchange was observed in the observational studies but not in the randomized controlled trials.

Two more randomized controlled trials ${ }^{17,18}$ were reported that are not included in the meta-analyses of Wijkstra and Kolodziej. ${ }^{34,35}$ Duiverman et al ${ }^{17}$ randomized 72 patients with COPD to nocturnal NIV in addition to rehabilitation 
$(n=37)$ or rehabilitation alone $(n=35)$. Inclusion criteria were stable clinical condition (no exacerbation in the 4 weeks prior to study participation, together with $\mathrm{pH}$ $>7.35)$, severe COPD $\left(\mathrm{FEV}_{1} / \mathrm{FVC}<70 \%\right.$ and $\mathrm{FEV}_{1}$ $<50 \%$ predicted), hypercapnia at rest $\left(\mathrm{P}_{\mathrm{aCO}_{2}}>45 \mathrm{~mm} \mathrm{Hg}\right.$ while breathing room air), and age $40-76$ years. Outcome measures of functional status and gas exchange were assessed before and after the 3-month intervention period. For those who completed the protocol, the mean inspiratory positive airway pressure (IPAP) was $20 \pm 4 \mathrm{~cm} \mathrm{H}_{2} \mathrm{O}$, the mean expiratory positive airway pressure (EPAP) was $6 \pm 2 \mathrm{~cm} \mathrm{H}_{2} \mathrm{O}$, the mean respiratory rate on NIV was $18 \pm 3$ breaths $/ \mathrm{min}$, the inspiration time was $0.9 \pm 0.2 \mathrm{~s}$, and the rise time was $1.2 \pm 0.6 \mathrm{~s}$. Most patients used an oronasal mask (70\%); the remaining used a nasal mask. Five patients $(16 \%)$ dropped out due to intolerance of NIV. Those who completed the protocol used NIV an average of $96 \%$ of the days, with a median daily NIV use of $7.7 \mathrm{~h}$ (interquartile range $5.8-8.5 \mathrm{~h} / \mathrm{d}$ ). The authors found that NIV augmented the benefits of pulmonary rehabilitation in patients with COPD and chronic hypercapnic respiratory failure, as it improved several measures of HRQL, functional status, and gas exchange.

McEvoy et $\mathrm{al}^{18}$ conducted a multicenter randomized controlled trial of NIV plus long-term oxygen therapy (LTOT) versus LTOT alone in 4 Australian university hospitals. Enrolled patients had severe stable smokingrelated COPD $\left(\mathrm{FEV}_{1}<1.5 \mathrm{~L}\right.$ or $<50 \%$ predicted and $\mathrm{FEV}_{1} / \mathrm{FVC}<60 \%$ with awake $\mathrm{P}_{\mathrm{aCO}_{2}}>46 \mathrm{~mm} \mathrm{Hg}$ and on LTOT for at least 3 months) and age $<80$ years. Patients with sleep apnea or morbid obesity were excluded. Outcome measures were survival, spirometry, arterial blood gases, polysomnography, general and disease-specific quality of life, and mood. One hundred forty-four patients were randomized (72 to NIV + LTOT, and 72 to LTOT alone). Adherence to NIV was $4.5 \pm 3.2 \mathrm{~h} / \mathrm{night}$; only $41 / 72$ patients $(60 \%)$ used NIV $>4$ h/night and were included in the per protocol analysis. IPAP was 12.9 (12.513.4) $\mathrm{cm} \mathrm{H}_{2} \mathrm{O}$ and EPAP was $5.1(4.8-5.3) \mathrm{cm} \mathrm{H}_{2} \mathrm{O}$. NIV was associated with an improvement in survival but no change in daytime arterial blood gases, pulmonary function measurements, or hospitalization rates. Diseasespecific and general quality of life did not improve with NIV. In fact, it appears that the addition of NIV to usual care in these severely disabled COPD patients resulted in deterioration in general and mental health and some aspects of mood. The authors concluded that nocturnal NIV in stable oxygen-dependent patients with hypercapnic COPD may improve survival, but this appears to be at the cost of worsening quality of life.

In a retrospective observational study, Oscroft et al ${ }^{29}$ evaluated the outcomes of 35 patients with a $\mathrm{P}_{\mathrm{aCO}_{2}}$ $>56 \mathrm{~mm} \mathrm{Hg}$ and normal $\mathrm{pH}$ following hospital admission with COPD exacerbation. Patients were initiated on long- term NIV; 4 patients were intolerant. NIV was titrated to a mean inspiratory pressure of $26 \pm 3 \mathrm{~cm} \mathrm{H}_{2} \mathrm{O}$ and expiratory pressure of $4 \pm 1 \mathrm{~cm} \mathrm{H}_{2} \mathrm{O} ; 77 \%$ used oronasal masks. Patients used NIV $8.4 \pm 3.5$ h/d. Daytime arterial blood gases and nocturnal ventilatory parameters improved significantly on NIV. Median survival was 28.6 months.

High intensity NIV is an approach that has been promoted by Windisch and colleagues. The first report of this approach was in 2002. ${ }^{36}$ After a period of acclimatization, patients were instructed to use NIV during the night and for up to $6 \mathrm{~h}$ during the day (total $14 \mathrm{~h} / \mathrm{d}$ ) until normocapnia was achieved. The time to reach normocapnia was $8.8 \pm 3.8$ days, and the mean hospital stay was $14.1 \pm 5.1$ days. From then on the ventilator was used at night and for up to $2 \mathrm{~h}$ during midday (total $10 \mathrm{~h} / \mathrm{d}$ ). Patients used a nasal mask. Ventilator settings were adjusted individually to normalize arterial blood gases, while maintaining the best comfort for the patient. The inspiratory pressure was increased stepwise until a further increase was not tolerated, after which the respiratory rate was increased beyond the spontaneous rate to establish passive ventilation. Further increases in respiratory rate were aimed at a progressive decrease of $\mathrm{P}_{\mathrm{aCO}}$ toward normocapnia. Patients were discharged when normocapnia $\left(\mathrm{P}_{\mathrm{aCO}_{2}} 37-43 \mathrm{~mm} \mathrm{Hg}\right)$ during NIV had been achieved or $\mathrm{P}_{\mathrm{aCO}}$ did not show a further decrease during NIV for a minimum of 3 days. Of the 14 patients enrolled, 11 continued with the therapy for at least 6 months post discharge. Inspiratory pressure and rate required to reach normocapnia were $30 \pm 4 \mathrm{~cm} \mathrm{H}_{2} \mathrm{O}$ (range $24-34 \mathrm{~cm} \mathrm{H}_{2} \mathrm{O}$ ) and respiratory rate $23 \pm 2$ breaths/min (range $20-$ 26 breaths/min).

In a retrospective study of 34 patients, Windisch et al evaluated 2-year survival, changes in lung function, and blood gases in patients with stable hypercapnic COPD in whom high intensity NIV was used. ${ }^{37}$ NIV was predominantly used during the night, but patients were also instructed to use NIV for up to $4 \mathrm{~h}$ during daytime if necessary to control symptoms. The mean ventilator settings were an inspiratory pressure of $27.7 \pm 5.9 \mathrm{~cm} \mathrm{H}_{2} \mathrm{O}$ (range $17-40 \mathrm{~cm} \mathrm{H}_{2} \mathrm{O}$ ), respiratory rate $20.8 \pm 2.5$ breaths/min (range 14-24 breaths/min), and inspiratory time $1.0 \pm 0.2 \mathrm{~s}$ (range $0.7-1.5 \mathrm{~s}$ ). $\mathrm{FEV}_{1}$ increased by a mean of $0.14 \mathrm{~L}$, $\mathrm{P}_{\mathrm{aCO}}$ decreased by a mean of nearly $7 \mathrm{~mm} \mathrm{Hg}$, and $\mathrm{P}_{\mathrm{aO}}$ could be increased by nearly $6 \mathrm{~mm} \mathrm{Hg}$ after 2 months of therapy. The authors suggest that earlier negative studies of NIV for stable COPD might have been due to lower levels of support than what was used in this study.

In another study, Windisch et al reported 2-year and 5 -year survival rates for 73 patients receiving high intensity NIV of $82 \%$ and $58 \%$, respectively. ${ }^{38}$ In a prospective crossover study performed in 17 patients with severe stable hypercapnic COPD, Dreher et al ${ }^{39}$ reported that highintensity NIV, compared to lower intensity NIV, resulted 
in significant improvements in exercise related dyspnea, daytime $\mathrm{P}_{\mathrm{aCO}}, \mathrm{FEV}_{1}$, vital capacity, and the Severe Respiratory Insufficiency Questionnaire Summary Score. In an assessment of sleep quality, Dreher et $\mathrm{al}^{40}$ reported that high inspiratory pressures used with long-term high intensity NIV produce acceptable sleep quality that is no worse than that produced by lower inspiratory pressures.

The reports of high intensity NIV are intriguing. Because the reports to date have all come from the same group of investigators, the generalizability of the results are unknown. Moreover, all of the data come from observational studies. The cost effectiveness of a program that requires a 2-week admission to the hospital is also unknown, and it is not known whether a similar program could be implemented on an out-patient basis.

Physical activity may be the strongest predictor of allcause mortality in patients with COPD ${ }^{41}$ A number of studies have evaluated NIV to augment exercise training in patients with COPD. ${ }^{12,42-52}$ Benefits of NIV during exercise in patients with COPD include greater walking distance, cycle endurance, and the reduction in minute ventilation during exercise ${ }^{48}$; improved exercise tolerance and dyspnea ${ }^{49}$; improvements in heart rate, systolic blood pressure, blood lactate, and oxygen consumption after training ${ }^{50}$; lactate/speed, maximum inspiratory pressure $\left(\mathrm{P}_{\operatorname{Imax}}\right)$, 6-min walk distance, leg fatigue, $\mathrm{S}_{\mathrm{pO}_{2}}$ /speed, oxygen consumption, and dyspnea better with NIV than with supplemental-oxygen. ${ }^{52}$ Interestingly, one study found that dyspnea and walking distance were not improved, due to the burden of carrying the ventilator and oxygen in a backpack (Fig. 1). ${ }^{51}$ At present, use of NIV during exercise training is limited to stationary exercise (eg, treadmill or cycle) until smaller portable equipment is available.

The overlap syndrome refers to patients who have both sleep-disordered breathing and COPD. ${ }^{53}$ Machado et al ${ }^{54}$ reported their experience in patients with COPD referred for LTOT. Patients with OSA symptoms were referred for polysomnography, and about $15 \%$ were confirmed to have the overlap syndrome. Marin et al ${ }^{55}$ reported that CPAP eliminated the additional mortality risk of OSA in overlap patients, compared to COPD-only patients. It should be noted that the appropriate therapy for the overlap syndrome is usually CPAP, not NIV.

In 1999, a consensus group published recommendations for the use of NIV in patients with stable COPD (Table 1). ${ }^{56}$ Overall, these recommendations seem reasonable today. Perhaps more important from a practical standpoint, reimbursement criteria of the Centers for Medicare and Medicaid Services are shown in Table 2. It is still unclear how NIV should be titrated if it is used in this population (eg, to comfort while awake, by polysomnography while asleep, to normalize blood gases). Evidence is lacking for benefit in the population of patients with se-

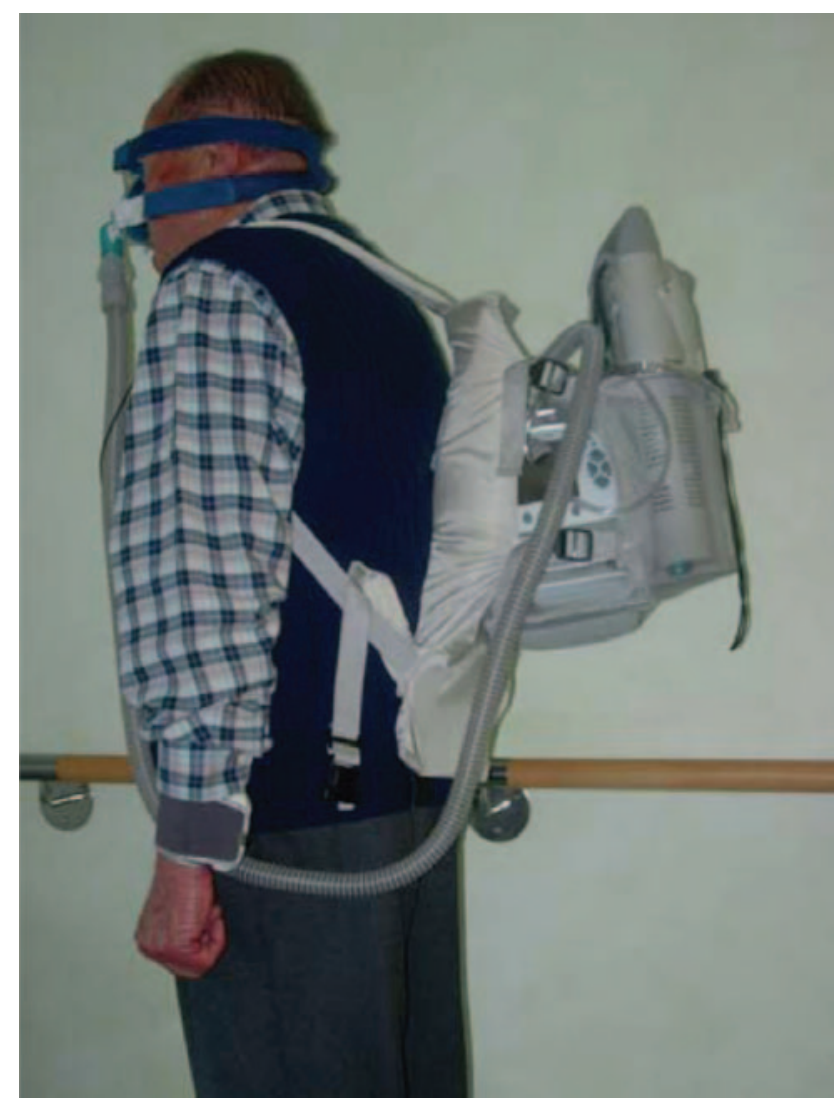

Fig. 1. A patient with COPD using noninvasive ventilation in addition to supplemental oxygen. (From Reference 51, with permission.)

Table 1. Indications for the Use of NIV in Patients With Stable COPD

1. Symptoms such as fatigue, dyspnea, and morning headache

2. Physiologic criteria (one of the following):

a. $\mathrm{P}_{\mathrm{aCO}_{2}} \geq 55 \mathrm{~mm} \mathrm{Hg}$

b. $\mathrm{P}_{\mathrm{aCO}_{2}}$ of $50-54 \mathrm{~mm} \mathrm{Hg}$ and nocturnal desaturation $\leq 88 \%$ for 5 continuous minutes while receiving oxygen therapy $\geq 2 \mathrm{~L} / \mathrm{min}$

c. $\mathrm{P}_{\mathrm{aCO}}$ of $50-54 \mathrm{~mm} \mathrm{Hg}$ and hospitalization related to recurrent episodes of hypercapnic respiratory failure ( $\geq 2$ in a 12 month period)

$\mathrm{NIV}=$ noninvasive ventilation

(Adapted from Reference 56.)

vere COPD, although individual patients might benefit. Perhaps benefit will occur with approaches like high intensity NIV, but this requires further study before it can be recommended. Use of NIV may be beneficial in some patients during exercise training, but the studies that have been reported to date have evaluated physiologic end points and not patient important outcomes. Moreover, current Medicare criteria will most likely not cover NIV for this application. 
Table 2. Medicare Coverage Criteria, NIV for Severe COPD

1. $\mathrm{P}_{\mathrm{aCO}} \geq 52 \mathrm{~mm} \mathrm{Hg}$ while awake and breathing the patient's usual $\mathrm{F}_{\mathrm{IO}_{2}}$

2. $\mathrm{S}_{\mathrm{pO}_{2}} \leq 88 \%$ for at least 5 continuous minutes, while breathing oxygen at $2 \mathrm{~L} / \mathrm{min}$ or the patient's usual $\mathrm{F}_{\mathrm{IO}_{2}}$ (whichever is higher).

3. Prior to initiating therapy, obstructive sleep apnea and treatment with CPAP has been considered and ruled out.

If above criteria are met, an E0470 device (without backup rate) is covered for 3 months.

An E0471 device (with backup rate) will not be covered for a patient with COPD during the first 2 months.

After $60 \mathrm{~d}$, an E0471 device will be covered if the following criteria are met:

1. $\mathrm{P}_{\mathrm{aCO}}$, repeated no sooner than $61 \mathrm{~d}$ after initiation of adherent use of the E0470, while awake and breathing the patient's usual $\mathrm{F}_{\mathrm{IO}_{2}}$, remains $\geq 52 \mathrm{~mm} \mathrm{Hg}$.

2. Sleep oximetry, repeated no sooner than $61 \mathrm{~d}$ after initiation of adherent use of an E0470 device, and while breathing with the E0470 device, demonstrates $\mathrm{S}_{\mathrm{pO}_{2}} \leq 88 \%$ for at least 5 continuous minutes, done while breathing oxygen at $2 \mathrm{~L} / \mathrm{min}$ or the patient's usual $\mathrm{F}_{\mathrm{IO}_{2}}$ (whichever is higher).

3. A signed and dated statement from the treating physician, completed no sooner than $61 \mathrm{~d}$ after initiation of the E0470 device, declaring that the patient has been adherent using the E0470 device (an average of $4 \mathrm{~h}$ per $24 \mathrm{~h}$ period) but that the patient is not benefiting from its use.

$\overline{\mathrm{NIV}}=$ noninvasive ventilation

\section{Cystic Fibrosis}

Cystic fibrosis (CF) is characterized by a progressive decline in lung function, which often progresses to endstage respiratory failure. A physiologic rationale can be made for the use of NIV in patients with acute and stable $\mathrm{CF}$, where it might unload respiratory muscles, relieve dyspnea, and improve alveolar ventilation and gas exchange. There have been a number of reports of the use of NIV for CF, but most have been short-term physiologic studies and observational reports. ${ }^{57-80}$ In a survey of the use of NIV for CF in France, Fauroux et al ${ }^{76}$ found that respiratory exacerbation was the most common criterion to initiate NIV. The primary indication for NIV in stable patients was diurnal hypercapnia, though certain other factors, such as respiratory sleep disturbance, were also important. It was also found that CF centers have high expectations about the potential benefits of NIV, but this contrasts with the lack of evidence of those benefits in this population. In an observational study, Fauroux et al ${ }^{77}$ evaluated the effect of 1 year of NIV on lung function in patients with advanced CF. Patients who used NIV $(n=41)$ were compared to matched controls $(n=41)$. They found that long-term NIV was associated with stabilization of the decline in lung function. However, patients were not randomized in a prospective manner, and selection bias may have favored the group receiving NIV. Validated criteria for selecting patients with CF for NIV are not available, and the long-term benefits of NIV in this patient population are not known. 80

Several studies have evaluated the use of NIV as an adjunct to airway clearance therapy in patients with CF. $64,72,75$ Fauroux et $\mathrm{al}^{64}$ found that the use of NIV during chest physiotherapy was associated with an improvement in respiratory muscle performance and with a reduction in oxygen desaturation. Holland et $\mathrm{al}^{72}$ evaluated the use of NIV during chest physiotherapy in 26 patients with $\mathrm{CF}$ and found that NIV improved inspiratory muscle function, oxygen saturation, small airway function, and dyspnea. Placidi et al ${ }^{75}$ evaluated 17 patients with $\mathrm{CF}$ and found no significant difference in sputum dry weight between mask positive expiratory pressure (PEP), CPAP, NIV, and directed cough. However, patients felt less tired after CPAP and NIV sessions than after mask PEP.

Three studies evaluated nocturnal NIV in patients with CF. ${ }^{62,68,78}$ Gozal et al ${ }^{62}$ conducted a single-night study in which patients received room air on the first trial night. If the patient exhibited substantial hypoxemia or hypercapnia, or both, the results were compared for a single overnight session of NIV and oxygen and to a single overnight session of oxygen. NIV improved sleep-related hypoxemia and hypercapnia, but did not affect sleep architecture and arousals. Milross et al ${ }^{68}$ also conducted a single-night trial of NIV (with or without oxygen), compared to an overnight session of low level CPAP and oxygen. Both NIV and oxygen therapy improved nocturnal $\mathrm{S}_{\mathrm{pO}_{2}}$, especially during rapid-eye-movement (REM) sleep. The rise in transcutaneous $\mathrm{P}_{\mathrm{CO}_{2}}$ with REM sleep was attenuated with NIV. Young et $\mathrm{al}^{78}$ conducted a randomized crossover study of NIV in 8 patients with CF and hypercapnia. Six weeks of NIV were compared with 6 weeks of placebo (no NIV). NIV improved the chest symptom score in a CF quality of life questionnaire, the transitional dyspnea index score, the nocturnal $\mathrm{P}_{\mathrm{tcCO}_{2}}$, and exercise performance. However, NIV did not improve sleep architecture, lung function, or awake $\mathrm{P}_{\mathrm{aCO}}$.

A Cochrane review has evaluated NIV for CF.79 The authors found that NIV may be a useful adjunct to airway clearance techniques, particularly in patients with $\mathrm{CF}$ who have difficulty expectorating sputum. They also found that NIV, when used in addition to oxygen, might improve gas exchange during sleep to a greater extent than oxygen therapy alone in patients with moderate to severe disease. These benefits of NIV have been demonstrated primarily in single treatment sessions with small numbers of subjects. The authors of this review conclude that the impact of NIV on exacerbations and disease progression remain unclear. They recommend adequately powered long-term randomized controlled trials to determine the clinical effects of NIV in CF. 
High level evidence is lacking to support the use of NIV in patients with stable CF. Its use seems reasonable in patients with severe disease and hypercapnia, in patients with sleep-disordered breathing, and in patients who become fatigued during chest physiotherapy. However, given the lack of robust evidence, the use of NIV for CF should be approached on an $n$-of- 1 basis, and reimbursement might be problematic.

\section{Restrictive Lung Disease}

\section{Restrictive Thoracic Disorders}

NIV has been used in the treatment of patients with restrictive thoracic disorders for many years. ${ }^{81-99}$ Potential mechanisms for benefit in this patient population include unloading of respiratory muscles and improvement in gas exchange. When NIV is used at night, it is hoped that these mechanisms will lead to better daytime gas exchange and less daytime fatigue.

In 49 patients with kyphoscoliosis, Marti et al ${ }^{98}$ reported a 5-year survival of $75 \%$. $\mathrm{P}_{\mathrm{aCO}_{2}} \geq 50 \mathrm{~mm} \mathrm{Hg}$ after 1 month of NIV and comorbidity (Charlson Index $\geq 3$ ) were independent predictors of mortality. In that same study, 61 patients with chest wall deformity due to tuberculosis sequelae experienced a 5 -year survival of $69 \%$. Jager et al ${ }^{96}$ retrospectively evaluated 188 patients; 85 received mechanical ventilation (all but 2 with NIV), and 103 received oxygen therapy alone. Mechanical ventilation was associated with a significantly better survival than oxygen therapy alone. After adjustments for age, sex, concomitant respiratory disease, blood gases, and vital capacity, the adjusted hazard risk of death was 0.35 (95\% CI 0.17 0.70). Gustafson et al ${ }^{92}$ retrospectively evaluated 100 patients who received mechanical ventilation (all but 3 with NIV), and 144 patients received oxygen therapy alone. Patients treated with mechanical ventilation had better survival, even when adjusting for age, sex, concomitant respiratory diseases, and blood gas levels, with a hazard ratio of 0.30 (95\% CI $0.18-0.51$ ). These studies, although retrospective and non-randomized, make a strong case for the use of NIV in patients with chest wall deformity. Ward et $\mathrm{al}^{91}$ studied a heterogeneous group of 47 patients with nocturnal hypoventilation secondary to neuromuscular disease, including some with chest wall deformity. They found that patients with neuromuscular disease and nocturnal hypoventilation are likely to deteriorate, with the development of daytime hypercapnia and/or progressive symptoms within 2 years, and thus might benefit from the use of nocturnal NIV before daytime hypercapnia ensues.

Menadue et al ${ }^{99}$ evaluated 13 patients with severe kyphoscoliosis who performed endurance treadmill tests in random order: sham pressure support, pressure support of $10 \mathrm{~cm} \mathrm{H}_{2} \mathrm{O}$, and high-level pressure support of $20 \mathrm{~cm} \mathrm{H}_{2} \mathrm{O}$.
Endurance time was significantly greater with a pressure support of $20 \mathrm{~cm} \mathrm{H}_{2} \mathrm{O}$. In a study by Borel et al, 979 patients exercised with NIV and 7 without NIV. Exercise training effects did not differ between patients training with or without NIV. This is in contrast to a previous study by Borel et al, ${ }^{95}$ in which they reported that NIV during exercise significantly improved exercise duration and tolerance and increased alveolar ventilation in patients with severe restrictive disease. Vila et $\mathrm{al}^{94}$ evaluated NIV and $15 \mathrm{~cm} \mathrm{H}_{2} \mathrm{O}$ pressure support with $4 \mathrm{~cm} \mathrm{H}_{2} \mathrm{O}$ PEEP in 8 patients with hypercapnia and kyphoscoliosis. They found that gas exchange, dyspnea, and perceived effort were improved with NIV.

A Cochrane review evaluated nocturnal mechanical ventilation for chronic hypoventilation in patients with neuromuscular and chest wall disorders. ${ }^{93}$ Eight eligible trials included 144 patients, most with neuromuscular disease and only a few with restrictive thoracic disorders. The authors concluded that current evidence about the therapeutic benefit of mechanical ventilation is weak, but consistent, and suggests alleviation of the symptoms of chronic hypoventilation. Further larger randomized trials are needed to confirm long-term beneficial effects of nocturnal mechanical ventilation on quality of life, morbidity, and mortality, to assess its cost-benefit ratio in chest wall diseases, and to compare the different types and modes of ventilation.

\section{Obesity Hypoventilation Syndrome}

OHS is defined as the triad of obesity, daytime hypoventilation, and sleep-disordered breathing in the absence of an alternative neuromuscular, mechanical, or metabolic explanation for hypoventilation. ${ }^{100,101}$ From 1986 to 2005 the prevalence of body mass index (BMI) $\geq 40 \mathrm{~kg} / \mathrm{m}^{2}$ has increased by 5 -fold, affecting 1 in every 33 adults. The prevalence of $\mathrm{BMI} \geq 50 \mathrm{~kg} / \mathrm{m}^{2}$ has also increased by 10 -fold, affecting 1 in every 230 adults. The prevalence of OHS is between $10 \%$ and $20 \%$ in obese patients with OSA, and is higher in the subgroup of patients with obstructive sleep apnea and extreme obesity. The most widely used therapy for managing OHS is CPAP or NIV.

Priou et al ${ }^{102}$ retrospectively evaluated 130 patients with OHS, either under stable conditions or during ICU management of acute hypercapnic exacerbation. Arterial blood gases and the Epworth sleepiness scale were significantly improved after 6 months of NIV. After a mean follow-up of $4.1 \pm 2.9$ years, 24 patients had died and 24 had discontinued NIV. The 1-, 2-, 3-, and 5-year survival probabilities were $97.5 \%, 93 \%, 88.3 \%$, and $77.3 \%$, respectively. Supplemental oxygen therapy was the only independent predictor of mortality. The probability of continuing NIV was $80 \%$ at 3 years with a high rate of daily use $(>7 \mathrm{~h})$, and female sex was predictive of lower long-term adher- 
ence. The authors concluded that NIV is an effective and well tolerated treatment of OHS, whether initiated in the acute or chronic setting.

Piper et al ${ }^{103}$ conducted a randomized trial of CPAP versus NIV for the treatment of OHS in 36 patients without severe nocturnal desaturation. There was no difference in adherence between the 2 groups, and both groups had similar improvements in symptoms. The authors concluded that both CPAP and NIV are equally effective in improving daytime hypercapnia. But these results may be relevant only in a subgroup of patients with OHS without severe nocturnal hypoxemia.

Redolfi et al ${ }^{104}$ evaluated $\mathrm{CO}_{2}$ sensitivity before and after nocturnal NIV in 6 patients with OHS. NIV was associated with improvements in gas exchange and $\mathrm{CO}_{2}$ chemosensitivity, and plasma leptin increased from after initiation in NIV. Heinemann et al ${ }^{105}$ evaluated 35 stable patients with OHS. They found that long-term domiciliary NIV normalized hypercapnia, markedly improved hypoxemia, and increased expiratory reserve volume. In a study of 15 patients with OHS, Chouri-Pontarollo ${ }^{106}$ found that the lower the daytime $\mathrm{CO}_{2}$ response, and the higher the proportion of REM sleep hypoventilation and daytime sleepiness, the better short-term therapy with NIV improved all of these parameters. In a study of 126 patients with OHS, Budweiser et al ${ }^{107}$ reported that gas exchange and lung function were improved after initiation of NIV. Hypoxemia, high $\mathrm{pH}$, and elevated inflammation markers predicted poor survival. Perez de Llano et al ${ }^{108}$ assessed the outcome of 54 patients with OHS who were treated with NIV, and found that it provided a significant improvement in clinical status and gas exchange. In a 12month study of the use of NIV in 13 patients with OHS, de Lucas-Ramos ${ }^{109}$ et al reported reductions in $\mathrm{P}_{\mathrm{aCO}_{2}}$ and increases in $\mathrm{P}_{\mathrm{aO}_{2}}, \mathrm{FVC}$, and ventilatory response to hypercapnia. Masa et $\mathrm{al}^{110}$ assessed the effectiveness of NIV in 22 patients with OHS, and in another group of 14 patients with kyphoscoliosis, and reported that NIV improved the clinical symptoms and the respiratory failure of patients with OHS to a degree similar to that reported with kyphoscoliosis.

Although the studies to date are observational and many are retrospective, the available evidence supports that NIV provides the benefits of CPAP (maintaining upper airway patency), while increasing tidal volume and alveolar ventilation. Long-term outcomes of NIV include improvement in blood gases, quality of life, and ventilatory response to $\mathrm{CO}_{2} \cdot{ }^{111}$ NIV should be considered the treatment of choice in patients with OHS if nocturnal hypoxemia is persistent despite an adequate CPAP titration. To be successful, the inspiratory pressure should be at least $8-10 \mathrm{~cm} \mathrm{H}_{2} \mathrm{O}$ above the expiratory pressure needed to eliminate obstructive respiratory events. ${ }^{112}$

\section{Neuromuscular Disease}

Neuromuscular respiratory failure can result from disease affecting the cerebral cortex, brainstem, basal ganglia, spinal cord, motor nerves, neuromuscular junction, and respiratory muscles. ${ }^{113}$ The respiratory effects of a wide range of neuromuscular diseases of various etiologies are similar. Consideration should be given to ability to ventilate, ability to cough, and aspiration risk.

Although all of the evidence is observational, there is little debate that NIV is life-prolonging in patients with Duchenne muscular dystrophy (DMD). Ishikawa et ${ }^{114}$ described survival in 3 groups of patients with DMD: group 1 patients were untreated (prior to 1984), group 2 patients underwent tracheotomy (1984-1991), group 3 patients were managed by noninvasive mechanical ventilation and cardioprotective medications (1992-present). The 56 patients of group 1 died at $18.6 \pm 2.9$ years of age; the 21 patients of group 2 died at $28.1 \pm 8.3$ years of age, with 3 still alive; and the 88 patients using NIV had 50\% survival to 39.6 years $(P<.001)$. Bach and Martinez ${ }^{115}$ described survival outcomes with NIV for full ventilatory support, and a mechanically assisted cough and oximetry protocol, in a series of patients with DMD. With advancing disease, 101 nocturnal-only NIV users extended their NIV use throughout the daytime hours and required it continuously for $7.4 \pm 6.1$ years to $30.1 \pm 6.1$ years of age, with 56 patients still alive. There were 8 tracheostomized patients decannulated to NIV, and 31 intubated patients were extubated to NIV plus mechanically assisted cough.

Guidelines for the respiratory management of DMD have been published. Recommendations from an expert panel were published in 2010, related to necessary equipment, procedures, tests, diagnostic evaluations, and a structured approach to the assessment and management of the respiratory complications of DMD. ${ }^{116}$ This document recommends use of nocturnal NIV when there are symptoms of hypoventilation, $\mathrm{S}_{\mathrm{pO}_{2}}<95 \%$ or end-tidal carbon dioxide pressure $\left(\mathrm{P}_{\mathrm{ETCO}_{2}}\right)>45 \mathrm{~mm} \mathrm{Hg}$, or when the apnea-hypopnea index is $>10$ events/h or 4 or more episodes of $\mathrm{S}_{\mathrm{pO}_{2}}<92 \%$, or drops in $\mathrm{S}_{\mathrm{pO}_{2}}$ of at least $4 \%$ per hour of sleep. Daytime NIV is recommended for self extension of nocturnal NIV into the waking hours, abnormal deglutition due to dyspnea that is relieved by respiratory assistance, inability to speak in full sentences due to dyspnea, and symptoms of hypoventilation, with $\mathrm{S}_{\mathrm{pO}_{2}}<95 \%$ and $\mathrm{P}_{\mathrm{ETCO}_{2}}>45 \mathrm{~mm} \mathrm{Hg}$ while awake. In 2007, a consensus statement was published on the respiratory management of patients with DMD undergoing anesthesia or sedation. ${ }^{117}$ For patients at increased risk of respiratory complications (FVC $<50 \%$ predicted, and especially for patients with $\mathrm{FVC}<30 \%$ predicted), it is recommended to consider preoperative training in the use of NIV. For 
patients at high risk of ineffective cough (peak cough flow $<270 \mathrm{~L} /$ min or peak expiratory pressure $>60 \mathrm{~cm} \mathrm{H}_{2} \mathrm{O}$ ), consider preoperative training in manual and mechanically assisted cough. It is also recommended to consider extubating patients with $\mathrm{FVC}<50 \%$ predicted, and especially those with FVC $<30 \%$ predicted, directly to NIV. In a consensus statement by the American Thoracic Society, ${ }^{118}$ nocturnal NIV is recommended for sleep-related upperairway obstruction and chronic respiratory insufficiency, and daytime ventilation is recommended when awake $\mathrm{P}_{\mathrm{aCO}}$ is $>50 \mathrm{~mm} \mathrm{Hg}$ or when daytime $\mathrm{S}_{\mathrm{pO}_{2}}<92 \%$.

NIV is also commonly used in patients with amyotrophic lateral sclerosis (ALS). Bourke et al conducted a randomized controlled trial to assess the effect of NIV on quality of life and survival in patients with ALS. Patients were assigned to NIV $(n=22)$ or standard care $(n=19)$ when they developed either orthopnea with $\mathrm{P}_{\text {Imax }}<60 \%$ of that predicted or symptomatic hypercapnia. NIV improved survival in the subgroup with better bulbar function, but not those with severe bulbar involvement. This subgroup showed improvement in several measures of quality of life, and a median survival benefit of 205 days $(P=.006)$. An evidence-based practice parameter by the American Academy of Neurology ${ }^{119}$ recommends that NIV should be considered to treat respiratory insufficiency in order to lengthen survival, that it may be considered to slow the decline of FVC and improve quality of life, and that early initiation may increase adherence. The authors of a Cochrane review concluded that evidence from a single randomized trial of NIV involving 41 participants (discussed above) suggests that it significantly improves and maintains quality of life and prolongs survival in patients with ALS. ${ }^{120}$

Several measures have been used to identify the appropriate time to initiate NIV in patients with respiratory muscle weakness associated with neuromuscular disease. An FVC $<50 \%$ predicted is the most common respiratory assessment used as an indication to initiate NIV. However, it may be a less sensitive indicator of respiratory muscle weakness than $\mathrm{P}_{\text {Imax }}$. A $\mathrm{P}_{\text {Imax }}>-60 \mathrm{~cm} \mathrm{H}_{2} \mathrm{O}$ is also used as an indication to initiate NIV. Mendoza et al ${ }^{121}$ reported that there were no cases among 161 patients where FVC $<50 \%$ antedated $\mathrm{P}_{\text {Imax }}>-60 \mathrm{~cm} \mathrm{H}_{2} \mathrm{O}$. Patients reached the $\mathrm{P}_{\text {Imax }}$ criterion 4-6.5 months earlier than the FVC criterion. In patients with diaphragm weakness, supine FVC (orthopnea) may be a better indicator of the time to initiate NIV than an erect FVC. A sniff nasal pressure can also be used, which is measured through a plug occluding one nostril during sniffs through the contralateral nostril. ${ }^{122}$ Overnight oximetry may be useful, as desaturation suggests nocturnal hypoventilation. The use of polysomnography to identify the need for NIV and titration of setting is controversial, although it is recommended in one consensus statement. ${ }^{118}$ Recommendations from a consensus
Table 3. Medicare Coverage Criteria, NIV for Restrictive Thoracic Disorders

1. Documentation in patient's medical record of a neuromuscular disease (eg, amyotrophic lateral sclerosis) or a severe thoracic cage abnormality (eg, post-thoracoplasty for tuberculosis); and

2. An arterial blood gas $\mathrm{P}_{\mathrm{aCO}}$, done while awake and breathing the patient's $\mathrm{F}_{\mathrm{IO}_{2}}$, is $\geq 45 \mathrm{~mm} \mathrm{Hg}$; or sleep oximetry demonstrates oxygen saturation $\leq 88 \%$ for $\geq 5$ min (minimum 2-h recording time), done while breathing the patient's prescribed $\mathrm{F}_{\mathrm{IO}_{2}}$; or for a neuromuscular disease (only), maximal inspiratory pressure is $<60 \mathrm{~cm} \mathrm{H}_{2} \mathrm{O}$ or $\mathrm{FVC}$ is $<50 \%$ predicted; and

3. COPD does not contribute substantially to the patient's pulmonary limitation.

If all of the above criteria are met, either an E0470 or E0471 (based upon the judgment of the treating physician) will be covered for patients within this group of conditions for the first 3 months of therapy.

$\mathrm{NIV}=$ noninvasive ventilation

committee suggest that NIV should be initiated in patients with neuromuscular disease with symptoms (such as fatigue, dyspnea, morning headache) and one of the following physiologic criteria: $\mathrm{P}_{\mathrm{aCO}_{2}} \geq 45 \mathrm{~mm} \mathrm{Hg}$, nocturnal oximetry demonstrating oxygen saturation $\leq 88 \%$ for 5 consecutive minutes; for progressive neuromuscular disease, $\mathrm{P}_{\text {Imax }}>-60 \mathrm{~cm} \mathrm{H}_{2} \mathrm{O}$ or $\mathrm{FVC}<50 \%$ predicted. Criteria for reimbursement are shown in Table 3.

NIV can be used to provide respiratory support during gastrostomy tube placement in patients with neuromuscular disease. Several case series have reported that this is safe in patients with ALS and DMD. ${ }^{123-130}$ Alternatively, the patient can be intubated for the procedure and extubated to NIV.

Successful extubation typically follows successful completion of a spontaneous breathing trial. Bach et al ${ }^{131}$ reported successful extubation of patients with neuromuscular disease and weakness who could not successfully complete a spontaneous breathing trial. Data were collected on 157 consecutive patients who could not pass a spontaneous breathing trial before or after extubation. The first-attempt protocol extubation success rate was $95 \%$; 6 of 8 patients who initially failed extubation succeeded on subsequent attempts, so only 2 underwent tracheotomy. These results, although observational, suggest the NIV can be used not only to prevent intubation and tracheostomy, but can also be used to allow successful extubation.

Some patients with a tracheostomy and chronic respiratory failure may be able to breathe without mechanical ventilation during the day, but still require nocturnal ventilation to manage hypoventilation and improve respiratory muscle function. These patients might also be successfully transitioned to NIV at night, with a capped tracheostomy tube, and ultimately decannulated (Fig. 2). ${ }^{132}$ 


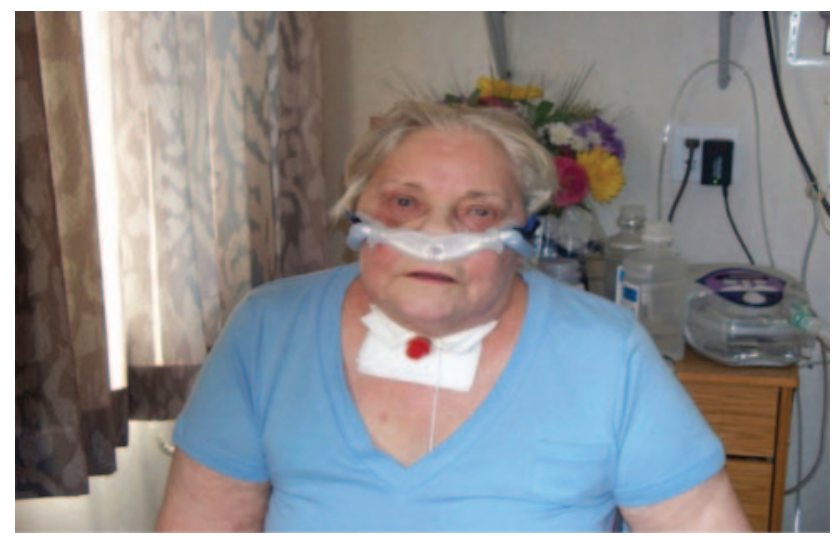

Fig. 2. Noninvasive ventilation via nasal pillows, with a capped tracheostomy tube. (From Reference 132.)

For patients with chronic respiratory failure, appropriate airway clearance is important in addition to support of ventilation. ${ }^{113,133}$ A peak cough flow $(\mathrm{PCF})>160 \mathrm{~L} / \mathrm{min}$ has been reported to predict success in extubation and decannulation. ${ }^{134}$ A PCF of $<160 \mathrm{~L} / \mathrm{min}$ has been used as a threshold for initiating cough-augmentation therapy for patients with neuromuscular disease and cough insufficiency. A PCF $<270 \mathrm{~L} / \mathrm{min}$ is considered a risk factor for complications associated with respiratory infection, because the PCF can fall below $160 \mathrm{~L} /$ min during respiratory infection. ${ }^{135}$ A peak expiratory pressure $<60 \mathrm{~cm} \mathrm{H}_{2} \mathrm{O}$ or a history of repeated hospitalization for respiratory infection and an inability to clear secretions are also indications for initiating cough-augmentation therapy. ${ }^{118}$ Cough augmentation techniques include manual cough augmentation, hyperinflation maneuvers, and mechanical in-exsufflation therapy. ${ }^{133,136}$

Despite the fact that many patients with chronic neuromuscular respiratory failure can be managed with NIV, tracheostomy becomes necessary for some. Indications for tracheostomy include intolerance of NIV, complications associated with NIV, aspiration of upper airway secretions, repeated lower-respiratory-tract infections despite aggressive cough augmentation, and patient wishes.

\section{Equipment Needs}

In the past, negative pressure ventilators were used for long-term NIV. However, these devices are nearly extinct today, with positive pressure ventilators now predominating. The success of NIV is to a large extent dependent on the selection of an appropriate interface, ventilator, and ventilator settings. But equally important is the understanding of the clinical team on the use of this equipment and appropriate training of the patient, family, and caregivers. Specific issues related to equipment for NIV are discussed in detail elsewhere. ${ }^{137-140}$

\section{Interface}

The interface is the weak link in the application of NIV. Desirable characteristics of an interface are listed in Table 4. The most commonly used interfaces are nasal masks and oronasal masks, and there are advantages and disadvantages of each (Table 5). Other interfaces used for chronic respiratory failure include nasal pillows, total face masks, and mouthpieces. Many sizes and designs are commercially available.

The nasal mask fits just above the junction of the nasal bone and cartilage, directly at the sides of both nares, and just below the nose above the upper lip. Some are gelfilled and others use an open cushion with an inner lip, in which pressure inside the mask pushes the cushion against the face. Nasal pillows, sometimes called nasal prongs or cushions, are available from several manufacturers. This interface consists of soft plastic plugs inserted into the nares, shaped in a way that the pressure applied during inspiration helps to seal the wall of the pillows against the inner surface of the nasal vestibule.

In a crossover design, Navalesi et al ${ }^{141}$ assessed 26 stable hypercapnic patients with restrictive thoracic disease or COPD who were naïve to NIV. They reported that the nasal mask was better tolerated than the other interfaces, but $\mathrm{P}_{\mathrm{aCO}}$ was lower with an oronasal mask than with nasal mask, and minute ventilation was higher with oronasal mask than with nasal mask. A criticism of this study ${ }^{141}$ is that the authors used a very comfortable nasal mask (gel cushion) but a less comfortable oronasal mask (air inflatable cushion). In a randomized crossover trial involving 24 healthy volunteers, Holanda et al ${ }^{142}$ evaluated adverse effects and comfort of total face masks, oronasal masks, and nasal masks during NIV. They found no differences among the masks in terms of comfort score, respiratory rate, heart rate, and $\mathrm{S}_{\mathrm{pO}_{2}}$. No differences in adverse effects were ob-

Table 4. Desirable Characteristics of an Interface for NIV

\author{
Low dead space \\ Transparent \\ Lightweight \\ Easy to secure \\ Adequate seal with low facial pressure \\ Disposable or easy to clean \\ Non-irritating (non-allergenic) \\ Inexpensive \\ Variety of sizes: adult and pediatric \\ Adaptable to variations in facial anatomy \\ Ability to be removed quickly \\ Anti-asphyxia mechanism \\ Compatible with wide range of ventilators
}

$\overline{\mathrm{NIV}}=$ noninvasive ventilation

(Adapted from Reference 137.) 
Table 5. Advantages and Disadvantages of Various Interfaces for NIV

\begin{tabular}{|c|c|c|}
\hline Interface & Advantages & Disadvantages \\
\hline Nasal mask & $\begin{array}{l}\text { Less risk for aspiration } \\
\text { Easier secretion clearance } \\
\text { Less claustrophobia } \\
\text { Easier speech } \\
\text { May be able to eat } \\
\text { Easy to fit and secure } \\
\text { Less dead space }\end{array}$ & $\begin{array}{l}\text { Mouth leak } \\
\text { Higher resistance through } \\
\text { nasal passages } \\
\text { Less effective with nasal } \\
\text { obstruction } \\
\text { Nasal irritation and } \\
\text { rhinorrhea } \\
\text { Mouth dryness }\end{array}$ \\
\hline Oronasal mask & $\begin{array}{l}\text { Better oral leak control } \\
\text { More effective in mouth } \\
\text { breathers }\end{array}$ & $\begin{array}{l}\text { Increased dead space } \\
\text { Claustrophobia } \\
\text { Increased aspiration risk } \\
\text { Increased difficulty } \\
\text { speaking and eating } \\
\text { Asphyxiation with } \\
\text { ventilator malfunction }\end{array}$ \\
\hline Mouthpiece & $\begin{array}{l}\text { Less interference with } \\
\text { speech } \\
\text { Very little dead space } \\
\text { May not require headgear }\end{array}$ & $\begin{array}{l}\text { Less effective if patient } \\
\text { cannot maintain mouth } \\
\text { seal } \\
\text { Usually requires nasal or } \\
\text { oronasal interface at } \\
\text { night } \\
\text { Potential for orthodontic } \\
\text { injury }\end{array}$ \\
\hline $\begin{array}{c}\text { Total face } \\
\text { mask }\end{array}$ & $\begin{array}{l}\text { May be more comfortable } \\
\text { for some patients } \\
\text { Easier to fit (one size fits } \\
\text { all) } \\
\text { Less facial skin breakdown }\end{array}$ & $\begin{array}{l}\text { Potentially greater dead } \\
\text { space } \\
\text { Potential for drying of the } \\
\text { eyes } \\
\text { Cannot deliver aerosolized } \\
\text { medications }\end{array}$ \\
\hline Nasal pillows & $\begin{array}{l}\text { Advantages of nasal mask, } \\
\text { but more comfortable } \\
\text { Less risk of facial skin } \\
\text { breakdown than nasal } \\
\text { mask }\end{array}$ & Same as nasal mask \\
\hline Hybrid & $\begin{array}{l}\text { Combines advantages of } \\
\text { mouthpiece and nasal } \\
\text { pillows }\end{array}$ & Same as oronasal mask \\
\hline
\end{tabular}

served. The full face mask avoided pain on the bridge of the nose and presented no air leaks around the eyes and mouth. A criticism of this study is that it was conducted in healthy volunteers and thus the implications for long-term ventilation are unclear. ${ }^{143}$

Willson et al ${ }^{144}$ studied the effectiveness of a nasal mask versus an oronasal mask in patients with nocturnal hypoventilation. They reported that the type of interface did not affect gas exchange, and arousal indices were comparable for both masks. Meyer et $\mathrm{al}^{145}$ assessed the frequency of occurrence and effect on sleep quality of air leaking through the mouth during nocturnal nasal ventilation in 6 patients with chest wall and neuromuscular disease using nocturnal nasal NIV. All patients had air leak-

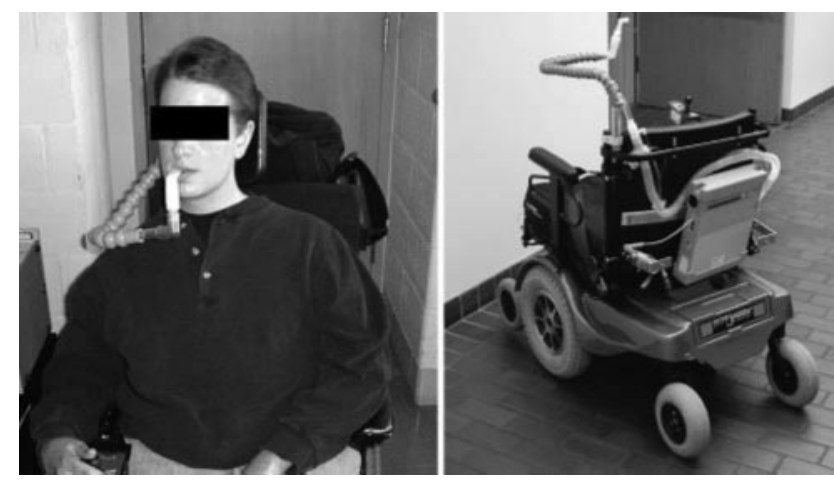

Fig. 3. Mouthpiece ventilation. Left: Patient with mouthpiece and ventilator circuit in standard position. Right: Rear view of wheelchair with ventilator and mouthpiece circuit in place. (From Reference 148.)

ing through the mouth for the majority of sleep, and air leaking through the mouth was associated with frequent arousals during lighter stages of sleep that interfered with progression to deeper stages, thus compromising sleep quality. Teschler et al ${ }^{146}$ found that mouth leak reduced effective respiratory support, increased transcutaneously measured partial pressure of carbon dioxide $\left(\mathrm{P}_{\mathrm{tcCO}_{2}}\right)$, and disrupted sleep architecture.

Leaks through the mouth are common with a nasal interface. This can affect comfort, it can result in dry mouth, it can result in less effective ventilation, it can affect patient-ventilator interaction (trigger and cycle), and it can disrupt sleep architecture. ${ }^{139}$ The patient can be coached to keep the mouth closed, but this may be ineffective, particularly during sleep. A chin strap can be tried, and the current generation of chin straps can be quite effective. Willson et al ${ }^{144}$ found the chin strap effective in 14 of 16 subjects. Gonzalez et al ${ }^{147}$ reported that a chin strap can reduce air leak and $\mathrm{P}_{\mathrm{aCO}_{2}}$. However, the chin strap was effective only in about a third of patients. If persistent mouth leak occurs, an oronasal mask is often required. A nasal interface can be used during the daytime, and an oronasal mask is used at night to minimize mouth leak and improve sleep quality.

A potential problem with nasal and oronasal masks is facial skin breakdown, which most commonly occurs on the bridge of the nose. Perhaps the most important approach to prevent skin breakdown is to avoid strapping the mask too tight. A mask that is too large or that is too small increases the likelihood of poor fit and facial soreness. A mask with a forehead spacer or an adjustable forehead arm can be used to reduce the pressure on the bridge of the nose. Hypoallergenic care tape can be applied to the bridge of the nose, but this is less effective after substantial skin breakdown has occurred. Commercially available material is available specifically for this purpose. One can also 
consider the use of a different interface (eg, nasal pillows, mouthpiece, total face mask, or different manufacturer).

A small, angled mouthpiece or straw-type mouthpiece has been used for many years for NIV in patients with chronic respiratory failure (Fig. 3). Usually, the patient uses a mouthpiece during the day, but changes to a nasal or oronasal mask at night. The typical setup involves the use of a portable ventilator. ${ }^{148}$ Although the circuit is open, the pressure in the circuit prevents a low-pressure alarm. ${ }^{149}$ The respiratory rate is set on a low setting so that the patient can take breaths as needed, without the ventilator triggering when a breath is not needed. The patient activates the breath by placing the mouth on the mouthpiece and creating a small negative pressure in the circuit by sipping or inhaling. Some of the breath is lost to leak around the lips, so the tidal volume is set higher than what would be set otherwise. Tidal volume is set per the patient's comfort, typically in the range is of $0.7-1.2 \mathrm{~L}$. The mouthpiece can be mounted close to the head so that the patient can speak after each breath. Some mouthpieces are configured with a lip seal to minimize air leak. In a report by Bach et al ${ }^{150}$ of 257 patients with acute or chronic respiratory failure, mouth NIV was the predominant method of daytime ventilator support in 228 of the patients. Mouthpiece NIV was also used by 163 patients, of whom 61 had little or no measurable vital capacity. A lip seal or custom orthodontic interface was used for nocturnal mouthpiece NIV. Toussaint et al ${ }^{151}$ evaluated daytime mouthpiece ventilation in 42 patients with DMD, and found it to be safe and to prolong survival.

The pressure on facial structures from the mask has been associated with flattening of facial structures in children, because forces responsible for the broadening and outward growth of the face can be counteracted by the inward pressure exerted by the mask. ${ }^{152}$ This causes facial flattening, particularly of the mid-face, ${ }^{153,154}$ and malocclusion with retrusion of the maxillary ridge (class III angle malocclusion). ${ }^{154,155}$ Fauroux et al ${ }^{155}$ quantified mask-related facial injuries and reported that global facial flattening was present in $68 \%$ of the children: $43 \%$ had flattening of the forehead, $38 \%$ had flattening of the malar area, and $28 \%$ had flattening of the maxilla. A concave face was reported in $12 \%$ of the children. Maxillary retrusion was found in $37 \%$ and was seen more commonly when the nasal mask was used. Facial flattening was not associated with patient age, cumulative use of nasal NIV, or underlying disease. Skin injury was much more common in children greater than 10 years of age. Young children treated with NIV should be followed by an orthodontist so that necessary mask adjustments can be made or corrective orthotic devices can be employed. ${ }^{154}$

\section{Ventilator}

Table 6 lists considerations in the selection of a ventilator for NIV. There are 3 types of circuits commonly used with positive pressure ventilators for NIV. Dual limb circuits, such as those used with critical care ventilators, have inspiratory and expiratory valves, and separate hoses for the inspiratory and the expiratory gases. For portable ventilators, such as those typically used for ventilation in the home, a single limb circuit is used with an exhalation valve near the patient. The expiratory valve is actively closed during the inspiratory phase to prevent loss of delivered tidal volume. Because the expiratory valve is near the patient, rebreathing is minimized. For bi-level pressure ventilators, a single limb circuit is used. A leak port is present, which serves as a passive exhalation port for the patient. In some configurations, the leak port is incorporated into the circuit near the patient. In other configurations, the leak port is incorporated into the interface.

Bi-level pressure ventilators are blower devices that deliver inspiratory and expiratory pressures. They typically provide pressure support ventilation (PSV) or pressure controlled ventilation (PCV); the difference between the IPAP and EPAP is the level of pressure support (or pressure control). These ventilators use a single limb circuit with a passive exhalation port. For devices used in the home, supplemental oxygen, if required, is titrated into the circuit at the ventilator outlet or into the mask. $\mathrm{F}_{\mathrm{IO}_{2}}$ is determined by the oxygen flow, respiratory pattern, and leak.

Intermediate ventilators are commonly used for home care ventilation. Most current generation devices use a single limb circuit with an active exhalation valve near the patient. Older generations provided only volume controlled ventilation (VCV), but newer generations provide VCV, PCV, and PSV. Some of these are designed for either invasive or noninvasive ventilation. They vary in their ability to compensate for leaks; some compensate well and some not at all. Most have internal batteries, which power the ventilator for many hours, and can be mounted on a wheelchair.

Important to the function of ventilators for NIV is their ability to tolerate leaks. The function of bi-level pressure ventilators depends on the presence of a leak. Leaks include intentional leak through the passive exhalation port as well as any unintentional leaks that may be present in the circuit or at the interface. Some ventilators are able to detect unintentional leak and adjust flow to accommodate the leak. Leak detection algorithms must adjust for changes in leak with inspiratory and expiratory pressure changes, as well as changes that may occur breath-to-breath due to fit of the interface. Some newer generations of bi-level pressure ventilators use redundant leak estimation algorithms. Storre et al ${ }^{156}$ assessed leak compensation during $\mathrm{PCV}$ and VCV in 14 stable hypercapnic patients with COPD 
Table 6. Considerations in the Selection of a Ventilator for NIV

\section{Leak compensation}

Trigger and cycle coupled to patient's breathing pattern

Rebreathing

Oxygen delivery

Monitoring

Alarms (safety vs nuisance)

Portability

Battery life

Tamper-proof

Cost

$\mathrm{NIV}=$ noninvasive ventilation

(Adapted from Reference 137.)

receiving long-term NIV. Leak compensation decreased leakage-induced dyspnea. However, much of the additional inspiratory volume during PCV was lost via leakage. The authors concluded that leak compensation largely feeds the leak and results in only a marginal increase of tidal volume. PCV, but not VCV, resulted in clinically important leak compensation.

For long-term care, the clinician must decide among VCV, PCV, and PSV. There are advantages and disadvantages of either approach for NIV (Table 7). PSV is commonly used for NIV. A theoretical advantage of PSV is that it varies the inspiratory flow to meet patient demand, which should improve patient comfort during NIV. ${ }^{139}$ Girault et al $^{157}$ compared VCV and PSV in 15 patients with hypercapnic respiratory failure and reported that both modes similarly improved breathing pattern and gas exchange. The inspiratory work load was less with volume control, but patient comfort was greater with pressure support. In patients with stable CF, Fauroux et al ${ }^{67}$ reported that both pressure and volume ventilation decreased respiratory muscle unloading. In 13 ventilator-naïve patients with chest wall deformity, Struik et al ${ }^{158}$ compared volume-targeted and pressure-targeted ventilation in a randomized fashion. Two patients switched from volume to pressure ventilation due to lack of tolerance, but improvements in $\mathrm{P}_{\mathrm{aCO}_{2}}$ and $\mathrm{P}_{\mathrm{aO}}$ were not significantly different between the approaches. Available evidence has not shown any mode to be clearly superior to another for NIV. ${ }^{137}$

An issue of some controversy is whether or not a back-up rate is needed for NIV in patients with stable chronic respiratory failure. This has financial implications because, in the United States, reimbursement for a device with a backup rate (E0471 respiratory assistance device) is more than twice that for a device without a backup rate (E0470 respiratory assistance device). In a retrospective study of 182 post-tuberculosis patients receiving long-term NIV, Tsuboi et al ${ }^{159}$ found that patients treated with a pure controlled mode (rate determined by the ventilator) had longer survival rates than those treated with a mode that
Table 7. Comparison of Volume-Targeted Ventilation and Pressure-Targeted Ventilation for NIV in Patients With Neuromuscular Disease

Volume Ventilator
More complicated to use
Wide range of alarms
Constant tidal volume
Breath stacking possible
No leak compensation
Can be used without PEEP
Rebreathing minimized
Pressure Ventilator
Simple to use
Limited alarms
Variable tidal volume
Breath stacking not possible
Leak compensation
PEEP (expiratory positive airway pressure) always present
Rebreathing possible

NIV = noninvasive ventilation

(Adapted from Reference 137.)

allowed patient triggering. In fact, the 10-year probability of continuing NIV in those receiving the controlled mode was approximately 3 -fold higher. Dellweg et al ${ }^{160}$ measured blood gas values, respiratory muscle strength, spontaneous breathing pattern, and lung function before and after a 3-month period of NIV in 305 patients; 91\% of the patients were able to adapt to a controlled mode of NIV. They observed a significant reduction in daytime $\mathrm{P}_{\mathrm{aCO}}$, increased daytime $\mathrm{P}_{\mathrm{aO}_{2}}$, improved lung function, and improved maximum respiratory muscle strength after 3 months of NIV using the controlled mode. Fauroux et al ${ }^{73}$ evaluated the effect of a back-up rate on respiratory effort during NIV. The back-up rate was progressively increased to the maximum that patients could tolerate, which resulted in decreased respiratory effort in 10 patients with $\mathrm{CF}$. A back-up rate during NIV is particularly important in patients prone to hypoventilation with loss of wakefulness respiratory drive during sleep, such as those with neuromuscular disease ${ }^{161,162}$ or stable chronic alveolar hypoventilation syndromes. ${ }^{163}$

Proportional-assist ventilation (PAV) has been used to improve patient-ventilator synchrony during acute respiratory failure. ${ }^{164}$ In patients with chronic respiratory failure due to neuromuscular disease and chest-wall deformity, Hart et al ${ }^{165}$ found that PSV and PAV produced similar improvements in physiologic variables. However, greater diaphragm unloading was observed with PSV than with PAV, which was associated with greater symptomatic benefit. Porta et al ${ }^{166}$ compared the short-term physiologic effects of PSV and PAV in 11 patients with clinically stable COPD and 7 patients with restrictive chest-wall 
diseases. They reported that noninvasive PAV, set at the patient's comfort, was not superior to PSV in unloading the inspiratory muscles. Winck et al ${ }^{167}$ compared the tolerance and physiologic effects of a 5-night treatment with either nasal PAV or PSV in patients with chronic respiratory failure (4 with COPD and 10 with restrictive thoracic diseases). PAV and PSV had similar patient tolerance and were equally effective in reducing daytime hypercapnia and improving nocturnal oxygen saturation and symptoms. PAV was associated with less nasal and oral dryness, but with more alarm noise. Poggi et al ${ }^{168}$ compared PAV versus PSV in 8 male patients with chronic respiratory failure due to COPD. They found that PAV and PSV unload the diaphragm, but that PAV can be more efficient than PSV, by producing a greater minute ventilation for a similar rise in transdiaphragmatic pressure. Importantly, PAV is designed to only amplify patient effort. There is no minimal support provided in the setting of very weak or absent efforts.

Average volume-assured pressure support (AVAPS) maintains a tidal volume equal to or greater than the target tidal volume, by automatically controlling the minimum and maximum IPAP settings. AVAPS averages tidal volume over time and gradually changes the IPAP over several minutes to achieve the target tidal volume. If patient effort decreases, IPAP is increased to maintain the target tidal volume. On the other hand, if patient effort increases, IPAP is reduced. Because AVAPS is a form of adaptive pressure-controlled ventilation, there is a concern that the ventilator will inappropriately decrease support if respiratory drive increases. ${ }^{169}$ In 10 patients with OHS who did not respond to therapy with CPAP, the effects of NIV with PSV and AVAPS on ventilation pattern, gas exchange, sleep quality, and HRQL were assessed in a randomized crossover trial. ${ }^{170}$ NIV with PSV substantially improved oxygenation, sleep quality, and HRQL in patients with OHS. AVAPS provided additional benefits on ventilation quality, thus resulting in a more efficient decrease of $\mathrm{P}_{\mathrm{tcCO}}$, but this did not provide further clinical benefits regarding sleep quality and HRQL. In a single-blind randomized crossover study of 28 patients with chronic respiratory failure, Ambrogio et al ${ }^{171}$ found that AVAPS was comparable to PSV with regard to sleep efficiency.

Another type of adaptive pressure-controlled ventilation is intelligent volume-assured pressure support. This mode is designed to guarantee minimum alveolar ventilation, defined as minute ventilation minus anatomical dead-space ventilation. The level of pressure support is continuously adjusted by comparing the continuously updated estimate of alveolar ventilation with the target alveolar ventilation. Battisti et al ${ }^{172}$ evaluated this approach in 19 patients receiving NIV for acute hypercapnic respiratory failure. They found that the alveolar ventilation based control of PSV during NIV was feasible and led to beneficial effects in patients, comparable to manually set PSV. In a randomized crossover trial of 25 patients with COPD and chronic respiratory failure, Oscroft et al ${ }^{173}$ compared NIV with intelligent volume-assured pressure support to conventional PSV. Each treatment period consisted of 8 weeks. No significant differences were found in arterial blood gases, nocturnal oxygen saturation, or any of the secondary outcomes that included lung function, exercise capacity, nocturnal $\mathrm{P}_{\mathrm{tcCO}}$, health status, or adherence. The authors concluded that the 2 modes were equally effective in the longterm management of ventilatory failure associated with stable COPD. Jaye et al ${ }^{174}$ conducted a randomized crossover trial that compared NIV with intelligent volumeassured pressure support to PSV in 20 patients with neuromuscular and chest wall disease who required long-term ventilation for nocturnal hypoventilation. They found comparable control of nocturnal oxygenation without compromising sleep quality.

Rise time (pressurization rate) is the time required to reach the inspiratory pressure at the onset of the inspiratory phase with pressure support or pressure control ventilation. ${ }^{175}$ Rise time should be set to maximize patient comfort. Ramp settings reduce the initial pressure and then gradually increase it to the pressure setting. A ramp has been used primarily in patients receiving CPAP for sleep apnea, the objective being to allow the patient to fall asleep more comfortably. The role of a ramp during NIV is unclear. Although it might be considered to improve patient tolerance of NIV, it also delays the onset of effective respiratory support. Another embellishment of NIV is Bi-Flex, which inserts a small amount of pressure relief during the latter stages of inspiration and the beginning part of exhalation. Evidence supporting the use of Bi-Flex with NIV is anecdotal.

Although the use of humidification during NIV is controversial, ${ }^{176}$ it is commonly used to improve patient comfort and to prevent drying of the upper airway. Humidification can be provided by an active heated humidifier or a passive heat-and-moisture exchanger (HME). In a randomized crossover 12-month study, ${ }^{177} 16$ patients with stable chronic hypercapnic respiratory failure received either heated humidification or HME. At the end of the trial, 10 out of 14 surviving patients decided to continue with heated humidification. Lellouche et al ${ }^{178}$ reported that minute ventilation was significantly higher with an HME than with a heated humidifier for a similar $\mathrm{P}_{\mathrm{aCO}}$. Jaber et al ${ }^{179}$ reported that $\mathrm{P}_{\mathrm{aCO}}$ was significantly higher with an $\mathrm{HME}$ than with a heated humidifier, and concluded that the increased dead space of an HME may negatively affect respiratory function and gas exchange. Based on this evidence, the use of an HME during NIV is not recommended.

Ventilators for NIV can be battery-powered for safety and increased portability. Some ventilators that can be used for NIV have an internal battery. Others can be pow- 
ered with a battery or uninterruptable power supply. The duration of a fully charged battery is determined by the size of the battery, ventilator settings, amount of leak, and whether or not a humidifier is used. When using a battery, it is generally best not to use a humidifier if possible, as this will extend the life of the battery.

\section{Approaches to Intolerance}

The implementation of NIV is as much an art as a science. Initiation of NIV requires strategies to encourage patient tolerance of the therapy. In patients with neuromuscular respiratory failure, it is important for the patient to understand that NIV is life-prolonging. Selection of an appropriate interface is often key to success. Various interfaces should be made available and the patient should have some say in the selection of the interface. To acclimate the patient to the mask, sometimes it is helpful for the patient to practice applying the mask and adjusting the headgear for short periods without attaching the ventilator. When introducing the ventilator, it is helpful to begin with low pressures. Sometimes sub-therapeutic settings are used initially to acclimate the patient. However, it is important to titrate to therapeutic levels as quickly as possible. Humidification is important for patient comfort. Attention should be given to facial skin breakdown by adjusting the headgear, switching to an alternate interface, or applying tape to the face. For patients intolerant of nocturnal NIV, therapy can be used for short periods during the daytime while there is a distraction such as watching television or reading a book. Family support is essential. For example, in the patient with neuromuscular disease, a family member (or other care provider) is needed to place the mask and turn on the ventilator. For patients needing NIV during the daytime, consideration should be given to alternating interfaces, such as a mouthpiece during the daytime and a mask at night. Effective therapy requires motivation and close communication among the patient, family, respiratory therapist, and physician to address problems and assure effective therapy.

\section{Summary}

Despite the observational nature of most of the evidence, the use of NIV in the treatment of stable chronic respiratory failure is increasing. In some cases, such as the use of nocturnal NIV for unselected patients with stable COPD, it is not well supported by the available evidence. In other cases, such as chronic respiratory failure associated with neuromuscular disease, the preponderance of evidence supports the use of NIV. The success of NIV in this patient population depends on selection of an appropriate patient, selection of an appropriate interface, selec- tion of an appropriate ventilator and ventilator settings, the skills of the clinician, the motivation of the patient, and the support of the family.

\section{REFERENCES}

1. Janssens JP, Derivaz S, Breitenstein E, De Muralt B, Fitting JW, Chevrolet JC, et al. Changing patterns in long-term noninvasive ventilation: a 7-year prospective study in the Geneva Lake area. Chest 2003;123(1):67-79.

2. Lloyd-Owen SJ, Donaldson GC, Ambrosino N, Escarabill J, Farre R, Fauroux B, et al. Patterns of home mechanical ventilation use in Europe: results from the Eurovent survey. Eur Respir J 2005;25(6): 1025-1031.

3. Divo MJ, Murray S, Cortopassi F, Celli BR. Prolonged mechanical ventilation in Massachusetts: the 2006 prevalence survey. Respir Care 2010;55(12):1693-1698.

4. Dhand R, Johnson JC. Care of the chronic tracheostomy. Respir Care 2006;51(9):984-1001; discussion 1002-1004.

5. Bach JR, Campagnolo DI, Hoeman S. Life satisfaction of individuals with Duchenne muscular dystrophy using long-term mechanical ventilatory support. Am J Phys Med Rehabil 1991;70(3): 129-135.

6. Narayanaswami P, Bertorini TE. Longterm tracheostomy ventilation in neuromuscular diseases: patient acceptance and quality of life. Neurorehabil Neural Repair 2000;14(2):135-139.

7. Markstrom A, Sundell K, Lysdahl M, Andersson G, Schedin U, Klang B. Quality-of-life evaluation of patients with neuromuscular and skeletal diseases treated with noninvasive and invasive home mechanical ventilation. Chest 2002;5:1695-1700.

8. Pehrsson K, Olofson J, Larsson S, Sullivan M. Quality of life of patients treated by home mechanical ventilation due to restrictive ventilatory disorders. Respir Med 1994;88(1):21-28.

9. Ram FS, Picot J, Lightowler J, Wedzicha JA. Non-invasive positive pressure ventilation for treatment of respiratory failure due to exacerbations of chronic obstructive pulmonary disease. Cochrane Database Syst Rev 2004(1):CD004104.

10. Gay PC, Hubmayr RD, Stroetz RW. Efficacy of nocturnal nasal ventilation in stable, severe chronic obstructive pulmonary disease during a 3-month controlled trial. Mayo Clin Proc1996;71(6): 533-542.

11. Casanova C, Celli BR, Tost L, Soriano E, Abreu J, Velasco V, et al. Long-term controlled trial of nocturnal nasal positive pressure ventilation in patients with severe COPD. Chest 2000;118(6):15821590.

12. Garrod R, Mikelsons C, Paul EA, Wedzicha JA. Randomized controlled trial of domiciliary noninvasive positive pressure ventilation and physical training in severe chronic obstructive pulmonary disease. Am J Respir Crit Care Med 2000;162(4 Pt 1):1335-1341.

13. Diaz O, Begin P, Torrealba B, Jover E, Lisboa C. Effects of noninvasive ventilation on lung hyperinflation in stable hypercapnic COPD. Eur Respir J 2002;20(6):1490-1498.

14. Clini E, Sturani C, Rossi A, Viaggi S, Corrado A, Donner CF, et al. The Italian multicentre study on noninvasive ventilation in chronic obstructive pulmonary disease patients. Eur Respir J 2002;20(3): 529-538.

15. Renston JP, DiMarco AF, Supinski GS. Respiratory muscle rest using nasal BiPAP ventilation in patients with stable severe COPD. Chest 1994;105(4):1053-1060.

16. Diaz O, Begin P, Andresen M, Prieto ME, Castillo C, Jorquera J, et al. Physiological and clinical effects of diurnal noninvasive ventilation in hypercapnic COPD. Eur Respir J 2005;26(6): 1016-1023. 


\section{Noninvasive Ventilation in Patients Requiring Prolonged Mechanical Ventilation}

17. Duiverman ML, Wempe JB, Bladder G, Jansen DF, Kerstjens HA, Zijlstra JG, et al. Nocturnal non-invasive ventilation in addition to rehabilitation in hypercapnic patients with COPD. Thorax 2008; 63(12):1052-1057.

18. McEvoy RD, Pierce RJ, Hillman D, Esterman A, Ellis EE, Catcheside $\mathrm{PG}$, et al. Nocturnal non-invasive nasal ventilation in stable hypercapnic COPD: a randomised controlled trial. Thorax 2009;64(7): 561-566.

19. Strumpf DA, Millman RP, Carlisle CC, Grattan LM, Ryan SM, Erickson AD, et al. Nocturnal positive-pressure ventilation via nasal mask in patients with severe chronic obstructive pulmonary disease. Am Rev Respir Dis 1991;144(6):1234-1239.

20. Ambrosino N, Nava S, Bertone P, Fracchia C, Rampulla C. Physiologic evaluation of pressure support ventilation by nasal mask in patients with stable COPD. Chest 1992;101(2):385-391.

21. Lien TC, Wang JH, Chang MT, Kuo CD. Comparison of BiPAP nasal ventilation and ventilation via iron lung in severe stable COPD. Chest 1993;104(2):460-466.

22. Nava S, Ambrosino N, Rubini F, Fracchia C, Rampulla C, Torri G, et al. Effect of nasal pressure support ventilation and external PEEP on diaphragmatic activity in patients with severe stable COPD. Chest 1993;103(1):143-150.

23. Meecham Jones DJ, Paul EA, Jones PW, Wedzicha JA. Nasal pressure support ventilation plus oxygen compared with oxygen therapy alone in hypercapnic COPD. Am J Respir Crit Care Med 1995; 152(2):538-544.

24. Lin CC. Comparison between nocturnal nasal positive pressure ventilation combined with oxygen therapy and oxygen monotherapy in patients with severe COPD. Am J Respir Crit Care Med 1996; 154(2 Pt 1):353-358.

25. Krachman SL, Quaranta AJ, Berger TJ, Criner GJ. Effects of noninvasive positive pressure ventilation on gas exchange and sleep in COPD patients. Chest 1997;112(3):623-628.

26. Marangoni S, Vitacca M, Quadri A, Schena M, Clini E. Noninvasive haemodynamic effects of two nasal positive pressure ventilation modalities in stable chronic obstructive lung disease patients. Respiration 1997;64(2):138-144.

27. Highcock MP, Shneerson JM, Smith IE. Increased ventilation with NIPPV does not necessarily improve exercise capacity in COPD. Eur Respir J 2003;22(1):100-105.

28. Kohnlein T, Schonheit-Kenn U, Winterkamp S, Welte T, Kenn K. Noninvasive ventilation in pulmonary rehabilitation of COPD patients. Respir Med 2009;103(9):1329-1336.

29. Oscroft NS, Quinnell TG, Shneerson JM, Smith IE. Long-term non-invasive ventilation to manage persistent ventilatory failure after COPD exacerbation. Respirology 2010;15(5):818-822.

30. Tsuboi T, Oga T, Machida K, Sumi K, Oguri S, Sato A, et al. $\mathrm{PaCO}_{2}$ six months after the initiation of long-term noninvasive ventilation in patients with COPD. Intern Med 2011;50(6):563-570.

31. Tsolaki V, Pastaka C, Kostikas K, Karetsi E, Dimoulis A, Zikiri A, et al. Noninvasive ventilation in chronic respiratory failure: effects on quality of life. Respiration 2011;81(5):402-410.

32. Hill NS. Noninvasive ventilation has been shown to be ineffective in stable COPD. Am J Respir Crit Care Med 2000;161(3 Pt 1):689690; discussion 691.

33. Rossi A. Noninvasive ventilation has not been shown to be ineffective in stable COPD. Am J Respir Crit Care Med 2000;161 (3 Pt 1):688-689.

34. Wijkstra PJ, Lacasse Y, Guyatt GH, Casanova C, Gay PC, Meecham Jones J, et al. A meta-analysis of nocturnal noninvasive positive pressure ventilation in patients with stable COPD. Chest 2003; 124(1):337-343.
35. Kolodziej MA, Jensen L, Rowe B, Sin D. Systematic review of noninvasive positive pressure ventilation in severe stable COPD. Eur Respir J 2007;30(2):293-306.

36. Windisch W, Vogel M, Sorichter S, Hennings E, Bremer H, Hamm $\mathrm{H}$, et al. Normocapnia during nIPPV in chronic hypercapnic COPD reduces subsequent spontaneous $\mathrm{PaCO}_{2}$. Respir Med 2002;96(8): 572-579.

37. Windisch W, Kostic S, Dreher M, Virchow JC, Jr., Sorichter S. Outcome of patients with stable COPD receiving controlled noninvasive positive pressure ventilation aimed at a maximal reduction of $\mathrm{PaCO}_{2}$. Chest 2005;128(2):657-662.

38. Windisch W, Haenel M, Storre JH, Dreher M. High-intensity noninvasive positive pressure ventilation for stable hypercapnic COPD. Int J Med Sci 2009;6(2):72-76.

39. Dreher M, Storre JH, Schmoor C, Windisch W. High-intensity versus low-intensity non-invasive ventilation in patients with stable hypercapnic COPD: a randomised crossover trial. Thorax 2010; 65(4):303-308.

40. Dreher M, Ekkernkamp E, Walterspacher S, Walker D, Schmoor C, Storre JH, et al. Non-invasive ventilation in COPD: impact of inspiratory pressure levels on sleep quality: a randomized cross-over trial. Chest 2011;140(4):939-945.

41. Waschki B, Kirsten A, Holz O, Muller KC, Meyer T, Watz H, et al. Physical activity is the strongest predictor of all-cause mortality in patients with COPD: a prospective cohort study. Chest 2011;140(2): 331-342.

42. Ambrosino N. Exercise and noninvasive ventilatory support. Monaldi Arch Chest Dis 2000;55(3):242-246.

43. Kyroussis D, Polkey MI, Hamnegard CH, Mills GH, Green M, Moxham J. Respiratory muscle activity in patients with COPD walking to exhaustion with and without pressure support. Eur Respir J 2000;15(4):649-655.

44. Johnson JE, Gavin DJ, Adams-Dramiga S. Effects of training with heliox and noninvasive positive pressure ventilation on exercise ability in patients with severe COPD. Chest 2002;122(2): 464-472.

45. Costes F, Agresti A, Court-Fortune I, Roche F, Vergnon JM, Barthelemy JC. Noninvasive ventilation during exercise training improves exercise tolerance in patients with chronic obstructive pulmonary disease. J Cardiopulm Rehabil 2003;23(4):307-313.

46. Hoo GW. Nonpharmacologic adjuncts to training during pulmonary rehabilitation: the role of supplemental oxygen and noninvasive ventilation. J Rehabil Res Dev 2003;40(5 Suppl 2):81-97.

47. Ambrosino N, Strambi S. New strategies to improve exercise tolerance in chronic obstructive pulmonary disease. Eur Respir J 2004; 24(2):313-322.

48. van 't Hul A, Gosselink R, Hollander P, Postmus P, Kwakkel G. Training with inspiratory pressure support in patients with severe COPD. Eur Respir J 2006;27(1):65-72.

49. Barakat S, Michele G, Nesme P, Nicole V, Guy A. Effect of a noninvasive ventilatory support during exercise of a program in pulmonary rehabilitation in patients with COPD. Int J Chron Obstruct Pulmon Dis 2007;2(4):585-591.

50. Toledo A, Borghi-Silva A, Sampaio LM, Ribeiro KP, Baldissera V, Costa D. The impact of noninvasive ventilation during the physical training in patients with moderate-to-severe chronic obstructive pulmonary disease (COPD). Clinics (São Paulo) 2007; 62(2):113-120.

51. Dreher M, Doncheva E, Schwoerer A, Walterspacher S, Sonntag F, Kabitz HJ, et al. Preserving oxygenation during walking in severe chronic obstructive pulmonary disease: noninvasive ventilation versus oxygen therapy. Respiration 2009;78(2):154-160.

52. Borghi-Silva A, Mendes RG, Toledo AC, Malosa Sampaio LM, da Silva TP, Kunikushita LN, et al. Adjuncts to physical training 


\section{Noninvasive Ventilation in Patients Requiring Prolonged Mechanical Ventilation}

of patients with severe COPD: oxygen or noninvasive ventilation? Respir Care 2010;55(7):885-894.

53. Owens RL, Malhotra A. Sleep-disordered breathing and COPD: the overlap syndrome. Respir Care 2010;55(10):1333-1344; discussion 1344-1336.

54. Machado MC, Vollmer WM, Togeiro SM, Bilderback AL, Oliveira MV, Leitao FS, et al. CPAP and survival in moderate-to-severe obstructive sleep apnoea syndrome and hypoxaemic COPD. Eur Respir J 2010;35(1):132-137

55. Marin JM, Soriano JB, Carrizo SJ, Boldova A, Celli BR. Outcomes in patients with chronic obstructive pulmonary disease and obstructive sleep apnea: the overlap syndrome. Am J Respir Crit Care Med 2010;182(3):325-331.

56. Clinical indications for noninvasive positive pressure ventilation in chronic respiratory failure due to restrictive lung disease, COPD, and nocturnal hypoventilation-a consensus conference report. Chest 1999;116(2):521-534.

57. Hodson ME, Madden BP, Steven MH, Tsang VT, Yacoub MH. Non-invasive mechanical ventilation for cystic fibrosis patients-a potential bridge to transplantation. Eur Respir J 1991;4(5):524-527.

58. Piper AJ, Parker S, Torzillo PJ, Sullivan CE, Bye PT. Nocturnal nasal IPPV stabilizes patients with cystic fibrosis and hypercapnic respiratory failure. Chest 1992;102(3):846-850.

59. Henke KG, Regnis JA, Bye PT. Benefits of continuous positive airway pressure during exercise in cystic fibrosis and relationship to disease severity. Am Rev Respir Dis 1993;148(5):1272-1276.

60. Padman R, Nadkarni VM, Von Nessen S, Goodill J. Noninvasive positive pressure ventilation in end-stage cystic fibrosis: a report of seven cases. Respir Care 1994;39(7):736-739.

61. Regnis JA, Piper AJ, Henke KG, Parker S, Bye PT, Sullivan CE. Benefits of nocturnal nasal CPAP in patients with cystic fibrosis. Chest 1994;106(6):1717-1724.

62. Gozal D. Nocturnal ventilatory support in patients with cystic fibrosis: comparison with supplemental oxygen. Eur Respir J 1997; 10(9):1999-2003.

63. Granton JT, Kesten S. The acute effects of nasal positive pressure ventilation in patients with advanced cystic fibrosis. Chest 1998; 113(4):1013-1018.

64. Fauroux B, Boule M, Lofaso F, Zerah F, Clement A, Harf A, et al. Chest physiotherapy in cystic fibrosis: improved tolerance with nasal pressure support ventilation. Pediatrics 1999;103(3):E32.

65. Fauroux B, Itti E, Pigeot J, Isabey D, Meignan M, Ferry G, et al. Optimization of aerosol deposition by pressure support in children with cystic fibrosis: an experimental and clinical study. Am J Respir Crit Care Med 2000;162(6):2265-2271.

66. Sprague K, Graff G, Tobias DJ. Noninvasive ventilation in respiratory failure due to cystic fibrosis. South Med J 2000;93(10): 954-961.

67. Fauroux B, Pigeot J, Polkey MI, Isabey D, Clement A, Lofaso F. In vivo physiologic comparison of two ventilators used for domiciliary ventilation in children with cystic fibrosis. Crit Care Med 2001;29(11):2097-2105

68. Milross MA, Piper AJ, Norman M, Becker HF, Willson GN, Grunstein RR, et al. Low-flow oxygen and bilevel ventilatory support: effects on ventilation during sleep in cystic fibrosis. Am J Respir Crit Care Med 2001;163(1):129-134.

69. Granton JT, Shapiro C, Kesten S. Noninvasive nocturnal ventilatory support in advanced lung disease from cystic fibrosis. Respir Care 2002;47(6):675-681.

70. Madden BP, Kariyawasam H, Siddiqi AJ, Machin A, Pryor JA, Hodson ME. Noninvasive ventilation in cystic fibrosis patients with acute or chronic respiratory failure. Eur Respir J 2002;19(2): 310-313.
71. Serra A, Polese G, Braggion C, Rossi A. Non-invasive proportional assist and pressure support ventilation in patients with cystic fibrosis and chronic respiratory failure. Thorax 2002;57(1):50-54.

72. Holland AE, Denehy L, Ntoumenopoulos G, Naughton MT, Wilson JW. Non-invasive ventilation assists chest physiotherapy in adults with acute exacerbations of cystic fibrosis. Thorax 2003; 58(10):880-884.

73. Fauroux B, Louis B, Hart N, Essouri S, Leroux K, Clement A, et al. The effect of back-up rate during non-invasive ventilation in young patients with cystic fibrosis. Intensive Care Med 2004;30(4): 673-681.

74. Fauroux B, Nicot F, Essouri S, Hart N, Clement A, Polkey MI, et al. Setting of noninvasive pressure support in young patients with cystic fibrosis. Eur Respir J 2004;24(4):624-630.

75. Placidi G, Cornacchia M, Polese G, Zanolla L, Assael BM, Braggion $\mathrm{C}$. Chest physiotherapy with positive airway pressure: a pilot study of short-term effects on sputum clearance in patients with cystic fibrosis and severe airway obstruction. Respir Care 2006; 51(10):1145-1153.

76. Fauroux B, Burgel PR, Boelle PY, Cracowski C, Murris-Espin M, Nove-Josserand R, et al. Practice of noninvasive ventilation for cystic fibrosis: a nationwide survey in France. Respir Care 2008; 53(11):1482-1489.

77. Fauroux B, Le Roux E, Ravilly S, Bellis G, Clement A. Long-term noninvasive ventilation in patients with cystic fibrosis. Respiration 2008;76(2):168-174.

78. Young AC, Wilson JW, Kotsimbos TC, Naughton MT. Randomised placebo controlled trial of non-invasive ventilation for hypercapnia in cystic fibrosis. Thorax 2008;63(1):72-77.

79. Moran F, Bradley JM, Piper AJ. Non-invasive ventilation for cystic fibrosis. Cochrane Database Syst Rev 2009(1):CD002769.

80. Fauroux B. Why, when and how to propose noninvasive ventilation in cystic fibrosis? Minerva Anestesiol 2011.

81. Ellis ER, Grunstein RR, Chan S, Bye PT, Sullivan CE. Noninvasive ventilatory support during sleep improves respiratory failure in kyphoscoliosis. Chest 1988;94(4):811-815.

82. Hill NS, Eveloff SE, Carlisle CC, Goff SG. Efficacy of nocturnal nasal ventilation in patients with restrictive thoracic disease. Am Rev Respir Dis 1992;145(2 Pt 1):365-371.

83. Leger P. Long-term noninvasive ventilation for patients with thoracic cage abnormalities. Respir Care Clin N Am 1996;2(2): 241-252.

84. Masa JF, Celli BR, Riesco JA, Sanchez de Cos J, Disdier C, Sojo A. Noninvasive positive pressure ventilation and not oxygen may prevent overt ventilatory failure in patients with chest wall diseases. Chest 1997;112(1):207-213.

85. Gonzalez Lorenzo F, Diaz Lobato S, Perez Grueso F, Villamor Leon J. Noninvasive mechanical ventilation and corrective surgery for treatment of a child with severe kyphoscoliosis. Pediatr Pulmonol 2001;32(5):403-405.

86. Highcock MP, Smith IE, Shneerson JM. The effect of noninvasive intermittent positive-pressure ventilation during exercise in severe scoliosis. Chest 2002;121(5):1555-1560.

87. Shneerson JM, Simonds AK. Noninvasive ventilation for chest wall and neuromuscular disorders. Eur Respir J 2002;20(2):480-487.

88. Buyse B, Meersseman W, Demedts M. Treatment of chronic respiratory failure in kyphoscoliosis: oxygen or ventilation? Eur Respir J 2003;22(3):525-528.

89. Fuschillo S, De Felice A, Gaudiosi C, Balzano G. Nocturnal mechanical ventilation improves exercise capacity in kyphoscoliotic patients with respiratory impairment. Monaldi Arch Chest Dis 2003; 59(4):281-286. 
90. Gonzalez C, Ferris G, Diaz J, Fontana I, Nunez J, Marin J. Kyphoscoliotic ventilatory insufficiency: effects of long-term intermittent positive-pressure ventilation. Chest 2003;124(3):857-862.

91. Ward S, Chatwin M, Heather S, Simonds AK. Randomised controlled trial of non-invasive ventilation (NIV) for nocturnal hypoventilation in neuromuscular and chest wall disease patients with daytime normocapnia. Thorax 2005;60(12):1019-1024.

92. Gustafson T, Franklin KA, Midgren B, Pehrsson K, Ranstam J, Strom K. Survival of patients with kyphoscoliosis receiving mechanical ventilation or oxygen at home. Chest 2006;130(6): 1828-1833.

93. Annane D, Orlikowski D, Chevret S, Chevrolet JC, Raphael JC. Nocturnal mechanical ventilation for chronic hypoventilation in patients with neuromuscular and chest wall disorders. Cochrane Database Syst Rev 2007(4):CD001941.

94. Vila B, Servera E, Marin J, Diaz J, Gimenez M, Komaroff E, et al. Noninvasive ventilatory assistance during exercise for patients with kyphoscoliosis: a pilot study. Am J Phys Med Rehabil 2007;86(8): 672-677.

95. Borel JC, Wuyam B, Chouri-Pontarollo N, Deschaux C, Levy P, Pepin JL. During exercise non-invasive ventilation in chronic restrictive respiratory failure. Respir Med 2008;102(5):711-719.

96. Jager L, Franklin KA, Midgren B, Lofdahl K, Strom K. Increased survival with mechanical ventilation in posttuberculosis patients with the combination of respiratory failure and chest wall deformity. Chest 2008;133(1):156-160.

97. Borel JC, Verges S, Pepin JL, Vivodtzev I, Levy P, Wuyam B. Home exercise training with non-invasive ventilation in thoracic restrictive respiratory disorders: a randomised study. Respir Physiol Neurobiol 2009;167(2):168-173.

98. Marti S, Pallero M, Ferrer J, Rios J, Rodriguez E, Morell F, et al. Predictors of mortality in chest wall disease treated with noninvasive home mechanical ventilation. Respir Med 2010; 104(12):1843-1849.

99. Menadue C, Alison JA, Piper AJ, Wong KK, Hollier C, Ellis ER. High- and low-level pressure support during walking in people with severe kyphoscoliosis. Eur Respir J 2010;36(2):370-378.

100. Mokhlesi B. Obesity hypoventilation syndrome: a state-of-the-art review. Respir Care 2010;55(10):1347-1362; discussion 1363-1365.

101. Powers MA. The obesity hypoventilation syndrome. Respir Care 2008;53(12):1723-1730.

102. Priou P, Hamel JF, Person C, Meslier N, Racineux JL, Urban T, et al. Long-term outcome of noninvasive positive pressure ventilation for obesity hypoventilation syndrome. Chest 2010;138(1): 84-90.

103. Piper AJ, Wang D, Yee BJ, Barnes DJ, Grunstein RR. Randomised trial of CPAP vs bilevel support in the treatment of obesity hypoventilation syndrome without severe nocturnal desaturation. Thorax 2008;63(5):395-401.

104. Redolfi S, Corda L, La Piana G, Spandrio S, Prometti P, Tantucci C. Long-term non-invasive ventilation increases chemosensitivity and leptin in obesity-hypoventilation syndrome. Respir Med 2007; 101(6):1191-1195.

105. Heinemann F, Budweiser S, Dobroschke J, Pfeifer M. Non-invasive positive pressure ventilation improves lung volumes in the obesity hypoventilation syndrome. Respir Med 2007;101(6):1229-1235.

106. Chouri-Pontarollo N, Borel JC, Tamisier R, Wuyam B, Levy P, Pepin JL. Impaired objective daytime vigilance in obesity-hypoventilation syndrome: impact of noninvasive ventilation. Chest 2007;131(1):148-155.

107. Budweiser S, Riedl SG, Jorres RA, Heinemann F, Pfeifer M. Mortality and prognostic factors in patients with obesity-hypoventilation syndrome undergoing noninvasive ventilation. J Intern Med 2007;261(4):375-383.
108. Perez de Llano LA, Golpe R, Ortiz Piquer M, Veres Racamonde A, Vazquez Caruncho M, Caballero Muinelos O, et al. Short-term and long-term effects of nasal intermittent positive pressure ventilation in patients with obesity-hypoventilation syndrome. Chest 2005; 128(2):587-594.

109. de Lucas-Ramos P, de Miguel-Diez J, Santacruz-Siminiani A, Gonzalez-Moro JM, Buendia-Garcia MJ, Izquierdo-Alonso JL. Benefits at 1 year of nocturnal intermittent positive pressure ventilation in patients with obesity-hypoventi lation syndrome. Respir Med 2004; 98(10):961-967.

110. Masa JF, Celli BR, Riesco JA, Hernandez M, Sanchez De Cos J, Disdier C. The obesity hypoventilation syndrome can be treated with noninvasive mechanical ventilation. Chest 2001;119(4):1102-1107.

111. Piper AJ. Obesity hypoventilation syndrome-the big and the breathless. Sleep Med Rev 2011;15(2):79-89.

112. Mokhlesi B. Positive airway pressure titration in obesity hypoventilation syndrome: continuous positive airway pressure or bilevel positive airway pressure. Chest 2007;131(6):1624-1626.

113. Benditt JO. The neuromuscular respiratory system: physiology, pathophysiology, and a respiratory care approach to patients. Respir Care 2006;51(8):829-837; discussion 837-839.

114. Ishikawa Y, Miura T, Aoyagi T, Ogata H, Hamada S, Minami R. Duchenne muscular dystrophy: survival by cardio-respiratory interventions. Neuromuscul Disord 2011;21(1):47-51.

115. Bach JR, Martinez D. Duchenne muscular dystrophy: continuous noninvasive ventilatory support prolongs survival. Respir Care 2011; 56(6):744-750.

116. Birnkrant DJ, Bushby KM, Amin RS, Bach JR, Benditt JO, Eagle $\mathrm{M}$, et al. The respiratory management of patients with Duchenne muscular dystrophy: a DMD care considerations working group specialty article. Pediatric pulmonology 2010;45(8):739-748.

117. Birnkrant DJ, Panitch HB, Benditt JO, Boitano LJ, Carter ER, Cwik VA, et al. American College of Chest Physicians consensus statement on the respiratory and related management of patients with Duchenne muscular dystrophy undergoing anesthesia or sedation. Chest 2007;132(6):1977-1986.

118. Finder JD, Birnkrant D, Carl J, Farber HJ, Gozal D, Iannaccone ST, et al. Respiratory care of the patient with Duchenne muscular dystrophy: ATS consensus statement. Am J Respir Crit Care Med 2004;170(4):456-465.

119. Miller RG, Jackson CE, Kasarskis EJ, England JD, Forshew D, Johnston W, et al. Practice parameter update: The care of the patient with amyotrophic lateral sclerosis: drug, nutritional, and respiratory therapies (an evidence-based review): report of the Quality Standards Subcommittee of the American Academy of Neurology. Neurology 2009;73(15):1218-1226.

120. Radunovic A, Annane D, Jewitt K, Mustfa N. Mechanical ventilation for amyotrophic lateral sclerosis/motor neuron disease. Cochrane Database Syst Rev 2009(4):CD004427.

121. Mendoza M, Gelinas DF, Moore DH, Miller RG. A comparison of maximal inspiratory pressure and forced vital capacity as potential criteria for initiating non-invasive ventilation in amyotrophic lateral sclerosis. Amyotroph Lateral Scler 2007;8(2):106-111.

122. Lofaso F, Nicot F, Lejaille M, Falaize L, Louis A, Clement A, et al. Sniff nasal inspiratory pressure: what is the optimal number of sniffs? Eur Respir J 2006;27(5):980-982.

123. Sancho J, Servera E, Chiner E, Banuls P, Gomez-Merino E, Sancho-Chust JN, et al. Noninvasive respiratory muscle aids during PEG placement in ALS patients with severe ventilatory impairment. J Neurol Sci 2010;297(1-2):55-59.

124. Bach JR, Gonzalez M, Sharma A, Swan K, Patel A. Open gastrostomy for noninvasive ventilation users with neuromuscular disease. Am J Phys Med Rehabil 2010;89(1):1-6. 


\section{Noninvasive Ventilation in Patients Requiring Prolonged Mechanical Ventilation}

125. Park JH, Kang SW. Percutaneous radiologic gastrostomy in patients with amyotrophic lateral sclerosis on noninvasive ventilation. Arch Phys Med Rehabil 2009;90(6):1026-1029.

126. Birnkrant DJ, Ferguson RD, Martin JE, Gordon GJ. Noninvasive ventilation during gastrostomy tube placement in patients with severe duchenne muscular dystrophy: case reports and review of the literature. Pediatr Pulmonol 2006;41(2):188-193.

127. Watanabe M, Kanda T, Maruyama S, Ikeda Y, Endo K, Susa R, et al. Gastrectomy performed with noninvasive positive pressure ventilation for a patient with severe chronic obstructive pulmonary disease: report of a case. Surg Today 2005;35(8):696-699.

128. Gregory S, Siderowf A, Golaszewski AL, McCluskey L. Gastrostomy insertion in ALS patients with low vital capacity: respiratory support and survival. Neurology 2002;58(3):485-487.

129. Boitano LJ, Jordan T, Benditt JO. Noninvasive ventilation allows gastrostomy tube placement in patients with advanced ALS. Neurology 2001;56(3):413-414.

130. Pope JF, Birnkrant DJ, Martin JE, Repucci AH. Noninvasive ventilation during percutaneous gastrostomy placement in Duchenne muscular dystrophy. Pediatr Pulmonol 1997;23(6):468-471.

131. Bach JR, Goncalves MR, Hamdani I, Winck JC. Extubation of patients with neuromuscular weakness: a new management paradigm. Chest 2010;137(5):1033-1039.

132. O'Connor HH, White AC. Tracheostomy decannulation. Respir Care 2010;55(8):1076-1081.

133. Boitano LJ. Management of airway clearance in neuromuscular disease. Respir Care 2006;51(8):913-922; discussion 922-924.

134. Bach JR, Saporito LR. Criteria for extubation and tracheostomy tube removal for patients with ventilatory failure. A different approach to weaning. Chest 1996;110(6):1566-1571.

135. Bach JR, Ishikawa Y, Kim H. Prevention of pulmonary morbidity for patients with Duchenne muscular dystrophy. Chest 1997;112(4): 1024-1028.

136. Boitano LJ. Equipment options for cough augmentation, ventilation, and noninvasive interfaces in neuromuscular respiratory management. Pediatrics 2009;123 Suppl 4:S226-230.

137. Hess DR. Noninvasive ventilation in neuromuscular disease: equipment and application. Respir Care 2006;51(8):896-911; discussion 911-912.

138. Hess DR. Positive pressure ventilator. In: Elliott M, Nava S, Schonhofer B, editors. Noninvasive ventilation and weaning: principles and practice. London: Hodder Arnold, 2010.

139. Hess DR. Patient-ventilator interaction during noninvasive ventilation. Respir Care 2011;56(2):153-165; discussion 165-167.

140. Hess DR. Noninvasive ventilation and continuous positive airway pressure. In: Hess DR, MacIntyre NR, Mishoe SC, Galvin WF, editors. Respiratory care principles and practice, 2nd edition. Burlington: Jones and Bartlett, 2012.

141. Navalesi P, Fanfulla F, Frigerio P, Gregoretti C, Nava S. Physiologic evaluation of noninvasive mechanical ventilation delivered with three types of masks in patients with chronic hypercapnic respiratory failure. Crit Care Med 2000;28(6):1785-1790.

142. Holanda MA, Reis RC, Winkeler GF, Fortaleza SC, Lima JW, Pereira ED. Influence of total face, facial and nasal masks on shortterm adverse effects during noninvasive ventilation. J Bras Pneumol 2009;35(2):164-173.

143. Keenan SP, Winston B. Interfaces for noninvasive ventilation: does it matter? J Bras Pneumol 2009;35(2):103-105.

144. Willson GN, Piper AJ, Norman M, Chaseling WG, Milross MA, Collins ER, et al. Nasal versus full face mask for noninvasive ventilation in chronic respiratory failure. Eur Respir J 2004;23(4): 605-609.

145. Meyer TJ, Pressman MR, Benditt J, McCool FD, Millman RP, Natarajan R, et al. Air leaking through the mouth during nocturnal nasal ventilation: effect on sleep quality. Sleep 1997;20(7):561569 .

146. Teschler H, Stampa J, Ragette R, Konietzko N, Berthon-Jones M. Effect of mouth leak on effectiveness of nasal bilevel ventilatory assistance and sleep architecture. Eur Respir J 1999;14(6):1251-1257.

147. Gonzalez J, Sharshar T, Hart N, Chadda K, Raphael JC, Lofaso F. Air leaks during mechanical ventilation as a cause of persistent hypercapnia in neuromuscular disorders. Intensive Care Med 2003; 29(4):596-602.

148. Benditt JO. Full-time noninvasive ventilation: possible and desirable. Respir Care 2006;51(9):1005-1012; discussion 1012-1015.

149. Boitano LJ, Benditt JO. An evaluation of home volume ventilators that support open-circuit mouthpiece ventilation. Respir Care 2005; 50(11):1457-1461.

150. Bach JR, Alba AS, Saporito LR. Intermittent positive pressure ventilation via the mouth as an alternative to tracheostomy for 257 ventilator users. Chest 1993;103(1):174-182.

151. Toussaint M, Steens M, Wasteels G, Soudon P. Diurnal ventilation via mouthpiece: survival in end-stage Duchenne patients. Eur Respir J 2006;28(3):549-555

152. Panitch HB. Respiratory issues in the management of children with neuromuscular disease. Respir Care 2006;51(8):885-893; discussion 894-895.

153. Li KK, Riley RW, Guilleminault C. An unreported risk in the use of home nasal continuous positive airway pressure and home nasal ventilation in children: mid-face hypoplasia. Chest 2000; 117(3):916-918.

154. Villa MP, Pagani J, Ambrosio R, Ronchetti R, Bernkopf E. Midface hypoplasia after long-term nasal ventilation. Am J Respir Crit Care Med 2002;166(8):1142-1143.

155. Fauroux B, Lavis JF, Nicot F, Picard A, Boelle PY, Clement A, et al. Facial side effects during noninvasive positive pressure ventilation in children. Intensive Care Med 2005;31(7):965-969.

156. Storre JH, Bohm P, Dreher M, Windisch W. Clinical impact of leak compensation during non-invasive ventilation. Respir Med 2009; 103(10):1477-1483.

157. Girault C, Richard JC, Chevron V, Tamion F, Pasquis P, Leroy J, et al. Comparative physiologic effects of noninvasive assist-control and pressure support ventilation in acute hypercapnic respiratory failure. Chest 1997;111(6):1639-1648.

158. Struik FM, Duiverman ML, Meijer PM, Nieuwenhuis JA, Kerstjens $\mathrm{H}$, Wijkstra PJ. Adjustment to volume or pressure targeted noninvasive ventilation in patients with chest wall deformity: a pilot study. Respir Care 2011;56(10):1522-1525.

159. Tsuboi T, Oga T, Machida K, Chihara Y, Matsumoto $\mathrm{H}$, Niimi A, et al. Importance of ventilator mode in long-term noninvasive positive pressure ventilation. Respir Med 2009;103(12): 1854-1861.

160. Dellweg D, Schonhofer B, Haidl PM, Barchfeld T, Wenzel MD, Appelhans $\mathrm{P}$, et al. Short-term effect of controlled instead of assisted noninvasive ventilation in chronic respiratory failure due to chronic obstructive pulmonary disease. Respir Care 2007;52(12): 1734-1740.

161. Boitano LJ. Managing the patient with neuromuscular disease and respiratory insufficiency. Respir Care 2008;53(11):1434-1435.

162. Bourke SC, Gibson GJ. Sleep and breathing in neuromuscular disease. Eur Respir J 2002;19(6):1194-1201.

163. Berry RB, Chediak A, Brown LK, Finder J, Gozal D, Iber C, et al Best clinical practices for the sleep center adjustment of noninvasive positive pressure ventilation (NPPV) in stable chronic alveolar hypoventilation syndromes. J Clin Sleep Med 2010;6(5):491-509.

164. Kacmarek RM. Proportional assist ventilation and neutrally-adjusted ventilatory assist. Respir Care 2011;56(2):140-148; discussion $149-152$. 
165. Hart N, Hunt A, Polkey MI, Fauroux B, Lofaso F, Simonds AK. Comparison of proportional assist ventilation and pressure support ventilation in chronic respiratory failure due to neuromuscular and chest wall deformity. Thorax 2002;57(11):979-981.

166. Porta R, Appendini L, Vitacca M, Bianchi L, Donner CF, Poggi R, et al. Mask proportional assist vs pressure support ventilation in patients in clinically stable condition with chronic ventilatory failure. Chest 2002;122(2):479-488.

167. Winck JC, Vitacca M, Morais A, Barbano L, Porta R, TeixeiraPinto A, et al. Tolerance and physiologic effects of nocturnal mask pressure support vs proportional assist ventilation in chronic ventilatory failure. Chest 2004;126(2):382-388.

168. Poggi R, Appendini L, Polese G, Colombo R, Donner CF, Rossi A. Noninvasive proportional assist ventilation and pressure support ventilation during arm elevation in patients with chronic respiratory failure. A preliminary, physiologic study. Respir Med 2006;100(6): 972-979.

169. Mireles-Cabodevila E, Chatburn RL. Work of breathing in adaptive pressure control continuous mandatory ventilation. Respir Care 2009;54(11):1467-1472.

170. Storre JH, Seuthe B, Fiechter R, Milioglou S, Dreher M, Sorichter S, et al. Average volume-assured pressure support in obesity hypoventilation: A randomized crossover trial. Chest 2006;130(3):815-821.

171. Ambrogio C, Lowman X, Kuo M, Malo J, Prasad AR, Parthasarathy S. Sleep and non-invasive ventilation in patients with chronic respiratory insufficiency. Intensive Care Med 2009;35(2):306-313.

172. Battisti A, Tassaux D, Bassin D, Jolliet P. Automatic adjustment of noninvasive pressure support with a bilevel home ventilator in pa- tients with acute respiratory failure: a feasibility study. Intensive Care Med 2007;33(4):632-638.

173. Oscroft NS, Ali M, Gulati A, Davies MG, Quinnell TG, Shneerson $\mathrm{JM}$, et al. A randomised crossover trial comparing volume assured and pressure preset noninvasive ventilation in stable hypercapnic COPD. COPD 2010;7(6):398-403.

174. Jaye J, Chatwin M, Dayer M, Morrell MJ, Simonds AK. Autotitrating versus standard noninvasive ventilation: a randomised crossover trial. Eur Respir J 2009;33(3):566-571.

175. Hess DR. Ventilator waveforms and the physiology of pressure support ventilation. Respir Care 2005;50(2):166-186; discussion 183-186.

176. Branson RD, Gentile MA. Is humidification always necessary during noninvasive ventilation in the hospital? Respir Care 2010;55(2): 209-216; discussion 216.

177. Nava S, Cirio S, Fanfulla F, Carlucci A, Navarra A, Negri A, et al. Comparison of two humidification systems for long-term noninvasive mechanical ventilation. Eur Respir J 2008;32(2): 460-464.

178. Lellouche F, Maggiore SM, Deye N, Taille S, Pigeot J, Harf A, et al. Effect of the humidification device on the work of breathing during noninvasive ventilation. Intensive Care Med 2002;28(11): 1582-1589.

179. Jaber S, Chanques G, Matecki S, Ramonatxo M, Souche B, Perrigault PF, et al. Comparison of the effects of heat and moisture exchangers and heated humidifiers on ventilation and gas exchange during non-invasive ventilation. Intensive Care Med 2002;28(11): 1590-1594.

\section{Discussion}

Carson: We know that during COPD exacerbations NIV decreases the work of breathing. Moreover, these patients are coming in with auto-PEEP [intrinsic PEEP], and, theoretically, applied expiratory pressure helps them overcome that auto-PEEP to initiate breaths. However, in the non-exacerbated COPD patient is it possible that auto-PEEP is less, and thus applied expiratory pressure is unnecessary and could be harmful, increasing the work of breathing?

Hess: What you're suggesting is that NIV, particularly the EPAP or PEEP, could be contributing to dynamic hyperinflation and that could be harmful?

Carson: Right. Or they're having to exhale against pressure - something a chronically failing patient may not be able to do. Since the data are so marginal as to benefit, should we be routinely adding PEEP?

Hess: What you say is true for the bi-level devices that need a minimum amount of EPAP to prevent rebreathing and so forth. But for the RCTs [randomized controlled trials] that were done back in the 1990s, I think those studies pre-dated bi-level devices.

MacIntyre: They used ICU ventilators.

Hess: It's possible to set PEEP on those ventilators, but it's also possible to set no PEEP. I would have to go back and look at the individual studies; I don't know that they used PEEP in those studies. I suspect that maybe they did not.
MacIntyre: I think this area is horribly confusing, and Shannon brings up an excellent point. You could also argue the opposite: that in fact these people do have chronically high levels of intrinsic PEEP and, instead of 5 , maybe they need $8 \mathrm{~cm} \mathrm{H}_{2} \mathrm{O}$ of PEEP. I'm not saying we should, but I think it's very unclear what the EPAP level ought to be. They're often just set at 5 for no apparent reason.

Hess: Or the lowest level available. I think you might also argue that the Windisch high intensity NIV approach ${ }^{1,2}$ might contribute to auto-PEEP. It drives up the minute ventilation.

1. Windisch W, Kostić S, Dreher M, Virchow JC Jr, Sorichter S. Outcome of patients with stable COPD receiving controlled noninvasive positive pressure ventilation aimed at a maximal reduction of $\mathrm{P}_{\mathrm{aCO}}$. Chest 2005; 128(2):657-662. 
2. Dreher M, Storre JH, Schmoor C, Windisch W. High-intensity versus low-intensity noninvasive ventilation in patients with stable hypercapnic COPD: a randomised crossover trial. Thorax 2010;65(4):303-308.

MacIntyre: I was going to bring that point up, because I've heard Windisch speak on this issue, and I've seen the numbers and it blows me away.

Hess: No pun intended.

MacIntyre: That's right! Often in obstructive lung disease we tend to try to reduce support in the acute phase, because these people are so horribly inflated, and one of the reasons we allow hypercapnia is in an effort to get minute ventilation down and reduce some auto-PEEP. So this notion of suddenly trying to drive the lung to normocapnia-the exact opposite of permissive hypercapnia-with inspiratory pressures of 20 to $40 \mathrm{~cm}$ $\mathrm{H}_{2} \mathrm{O}$ and breathing frequencies of 24 breaths a minute. Using John Marini's algorithms ${ }^{1}$ they must have horrific levels of intrinsic PEEP, and yet for some reason Windisch seems to think this helps. I'm confused on the physiology of what's going on.

1. Marini JJ, Crooke PS. A general mathematical model for respiratory dynamics relevant to the clinical setting. Am Rev Respir Dis 1993;147(1):14-24.

Hess: I think that if you could drive down their $\mathrm{P}_{\mathrm{CO}_{2}}$ to normal, as Windisch does by having them on 8, 10, 12,15 hours a day of this, in the times that they're not on the ventilator their work of breathing must be incredible to try to maintain that $\mathrm{P}_{\mathrm{CO}_{2}}$.

MacIntyre: The other thing is that these reported pressures are pressures in the mask. I'm not sure it really translates to pressures inside the lung. But, still, it's an area I find terribly confusing.

White: One issue we run into that's kind of interesting is that we have pa- tients who come to the LTAC [longterm acute care facility] who are started on NIV and have $\mathrm{CO}_{2}$ of 52 to $55 \mathrm{~mm} \mathrm{Hg}$. With a good percentage of them, we're able to get them adherent and efficiently treated with NIV, and their $\mathrm{CO}_{2}$ falls to the mid-40s. Then we have to try to qualify the patient to go home, and in order to qualify them and get them home, that testing has to be done within 24-48 hours of discharge. You look at blood gases, and their $\mathrm{P}_{\mathrm{aCO}}$ is $48 \mathrm{~mm} \mathrm{Hg}$. Then we have a patient who is nicely adherent to NIV, doing well with it and wants to go home with it, and I can't get it approved. The system creates a problem for us. Do you have any comment on that?

Hess: It seems to me that the rules are really written for a patient with chronic stable COPD getting de novo NIV. It doesn't address the type of patient you're talking about at all, nor do any of the RCTs address the patient that you're talking about. All of the RCTs, to my knowledge, have taken patients who were at home and who were stable with COPD and a $\mathrm{P}_{\mathrm{CO}_{2}}$ of $55 \mathrm{~mm} \mathrm{Hg}$ or so, and then started them on nocturnal NIV. They aren't the patients who you're describing, who came to the emergency department of an acute care hospital, got started on NIV (for which there is an abundance of evidence that supports that as the right thing to do), and then 4 or 5 days later they're out in the wards and they're still on NIV half the day or at night. Then they come to you, and you can make the case that it's a patient you want to transition home on NIV. But the way that the rules are written now, I don't think it considers that scenario.

White: In that small subset of patients who have done well with NIV in the LTAC and we can't send them home on it, are they bouncing back to the short-term acute care hospitals because we couldn't provide them with the machine at home? I don't have those data. Anecdotally, we've had some of those reported, but getting our hands on that information is going to be a struggle in trying to build our argument to make a change.

Hess: It's really a data-free zone as far as I know, but it sounds like it would be ripe for a study for somebody like you to do, where those kinds of patients would be randomized to go home on NIV or not. I think a very important outcome would be how many days until their first readmission to an acute care facility.

Muldoon:* Do you have any guidance as to how we might answer an NIV patient who says, "I do not want to go on invasive mechanical ventilation, but if I can't breathe anymore, I'll take NIV round the clock for as long as it takes?" We've seen this get to days, weeks, and sometimes longer.

Hess: I help to care for patients with neuromuscular disease who are at home on 24/7 NIV and they've been like that for months and years or more. When a patient asks me about the alternatives, I will tell them that this is one of the alternatives, and if they choose to go that way, I will do whatever I can as an RT [respiratory therapist] to make that work for them. And if they prefer to have a tracheostomy, then I will work with them as an RT to the best of my abilities to get them stabilized with the trach.

Muldoon: The skin is holding up?

Hess: Yes, surprisingly well. Now, what can you do to address that? There are things you can do, like rotate interfaces. Another thing that is helpful is for the patient to use a mouthpiece in the daytime and an oronasal or nasal mask at night. I have patients who

\footnotetext{
* Sean R Muldoon MD MPH, Kindred Healthcare, Hospital Division, Louisville, Kentucky.
} 
use the oronasal mask sometimes, or use nasal pillows with a chin strap, and others who use the total face mask sometimes... so essentially rotating the pressure points on the skin. I tell patients to use barriers. I used to tell people to buy Duoderm, until they told me that it's very expensive and insurance doesn't pay for it, so now they usually just put a band-aid on their nose.

I instruct family members not to strap it on so tightly that it leaves a mark in the morning, that it's okay to have a little bit of a leak around the mask. However, for some patients, if there's a lot of leak around the mask, that makes it very uncomfortable for them, particularly if it's leaking around their eyes. I have had patients who have been on full-time or near fulltime NIV for months and months with no skin breakdown.

Nelson: This again raises the issue of sub-typing. I'm not sure I agree with the idea of sub-typing because I think that CCI [chronic critical illness] and neuromuscular disease are 2 distinct entities rather than subtypes. PMV [prolonged mechanical ventilation] is an overlap area, but in my mind these are 2 different diseases. And I think the issues of NIV for patients with CCI may very well be different.

In our experience, patients with CCI have skin breakdown no matter what we do: even the most meticulous nursing care can't stop it from happening. The patients with neuromuscular disease don't have the same sort of inflammatory condition, they' re not usually anasarcic, we can keep up better with their nutritional needs, and their skin is less of a problem.

I can count on one hand the number of patients over the last 10 years in our in-hospital respiratory care unit who were discharged to home. Because the issue isn't just the ventilator: these patients have systemic, ongoing illness, and they can't get by on care at home. So I think we have to keep making a distinction between patients who have CCI and other patients, like those with neuromuscular disease, who need PMV for a different reason.

Hess: I appreciate your point. When I heard you make that point this morning, that's when I considered changing the title of my talk. Because I think what I'm talking about is not CCI, but there's some overlap.

Nelson: But we could ask the question, is NIV a viable solution for some patients with CCI? To my knowledge, we do not have much if any data to answer that question right now.

Hess: Again, I think this is a datafree zone: I don't think we know. If I tried to write my entire paper on that question, I probably wouldn't have enough for one page.

Nelson: Many patients with CCI can't even survive an ambulance ride to get them home. If it's extremely important for them to die in their homes, as it is for some, then maybe something like this-NIV_- can get them in the ambulance all the way home and there long enough to die in the place they've chosen. NIV for the chronically critically ill presents important issues for research.

White: We have data over one year of 188 patients who came to the LTAC, who either came on or were started on NIV in the LTAC. I can't give you the specific number, but it's a single-digit number of people who were tracheotomized and ventilated who ended up on NIV. The rest were the typical group with COPD, congestive heart failure, and neuromuscular disease. We're putting those data into a paper, which may help inform the discussion about the use of NIV in the CCI/PMV population.

King: John Bach pointed out that, though there aren't any RCTs to show that mechanical ventilation gives Duchenne muscular dystrophy patients a longer life, there aren't any RCTs on parachutes, either, but many people use them when they jump out of planes.

This article is approved for Continuing Respiratory Care Education credit. For information and to obtain your CRCE

(free to AARC members) visit www.RCJournal.com 